\title{
Inferential revision in narrative texts: An ERP study
}

\author{
Ana Pérez ${ }^{1} \cdot$ Kate Cain ${ }^{2} \cdot$ María C. Castellanos $^{1} \cdot$ Teresa Bajo $^{1}$
}

Published online: 6 June 2015

(C) Psychonomic Society, Inc. 2015

\begin{abstract}
We evaluated the process of inferential revision during text comprehension in adults. Participants with high or low working memory read short texts, in which the introduction supported two plausible concepts (e.g., 'guitar/ violin'), although one was more probable ('guitar'). There were three possible continuations: a neutral sentence, which did not refer back to either concept; a no-revise sentence, which referred to a general property consistent with either concept (e.g., '...beautiful curved body'); and a revise sentence, which referred to a property that was consistent with only the less likely concept (e.g., '...matching bow'). Readers took longer to read the sentence in the revise condition, indicating that they were able to evaluate their comprehension and detect a mismatch. In a final sentence, a target noun referred to the alternative concept supported in the revise condition (e.g., 'violin'). ERPs indicated that both working memory groups were able to evaluate their comprehension of the text (P3a), but only high working memory readers were able to revise their initial incorrect interpretation (P3b) and integrate the new information (N400) when reading the revise sentence. Low working memory readers had difficulties inhibiting the no-longer-relevant interpretation and thus failed to revise their situation model, and they experienced problems integrating semantically related information into an accurate memory representation.
\end{abstract}

Ana Pérez

antiterrenal@gmail.com

1 Mind, Brain and Behavioral Research Centre (CIMCYC), Department of Experimental Psychology, University of Granada, C/ Profesor Clavera s/n, CIMCYC, 18011 Granada, Spain

2 Lancaster University, Lancaster, UK
Keywords Revising information · Inference making · Working memory $\cdot \mathrm{P} 3 \mathrm{a} \cdot \mathrm{P} 3 \mathrm{~b} \cdot \mathrm{N} 400$

Successful text comprehenders construct an integrated, coherent, and accurate mental representation of the state of affairs described by the text. The construction of this situation model requires the reader to go beyond a representation of the surface characteristics of the text by generating inferences and incorporating world knowledge from long-term memory (Kintsch $\&$ van Dijk, 1978). The construction of the situation model is a dynamic process (e.g., Kintsch, 1998; McNamara \& Magliano, 2009; Rapp \& van den Broek, 2005); the text is processed incrementally (e.g., word by word and sentence by sentence) and, therefore, the situation model is constantly being updated as the text unfolds. As each new piece of information is processed, it must be integrated with the mental representation constructed so far. This involves monitoring for comprehension to identify when and where additional processing, such as inference generation, is necessary to ensure coherence (Kintsch, 1998; Perfetti, Stafura, \& Adlof, 2013).

Comprehension monitoring is the metacognitive awareness that readers have about what they are reading (Wagoner, 1983). Baker (1985) distinguished two monitoring phases: evaluation and regulation. Evaluation, more recently defined as validation (Singer, 2013), refers to the process that allows readers to detect an inconsistency or mismatch in the text (e.g., Vauras, Kinnunen, Salonen, \& Lehtinen, 2008). Current evidence on this process in adult readers converges on the view that evaluation is a routine, passive, and nonstrategic reading activity that depends on both the activation of current information and the integration of that information with previous text information or world knowledge (Kendeou, 2014). On the other hand, regulation is associated with the repair processes that are necessary to incorporate the new information into the 
current memory representation (e.g., O’Brien, Rizzella, Albrecht, \& Halleran, 1998). According to Hacker (1998), comprehenders self-regulate their reading by asking themselves questions (evaluation) and updating their situation model (e.g., revising inconsistent information). Updating is a type of regulation that includes a broad category of processes and for coherent texts it is achieved with little cognitive cost. When a mismatch between the current situation model and new information is detected in the evaluation phase, the updating process will involve more than simply integrating just-read information into the situation model. In such instances, readers may revise the situation model by modifying or replacing information. Revision of the situation model can only be achieved if readers are able to adequately regulate their comprehension. Hereafter, we refer to regulation as a revision process.

The revision process is clearly a specific updating activity that involves the inhibition of an interpretation that was encoded into the situation model in favour of the new information (Rapp \& Kendeou, 2007). Interestingly, both the evaluation of mismatches and the revision of no longer relevant information can occur at an inferential processing level. For example, if the text supports the generation of a specific inference (e.g., 'A mouse was looking for something to eat while a bigger animal was waiting to hunt it,' which supports the inference of ' $c a t$ '), only readers who generate that inference will be able to detect a subsequent mismatch (e.g., 'The dog jumped out and scared the mouse ${ }^{11}$ ). Readers who detect that mismatch should then revise their situation model by replacing 'cat' with ' $d o g$ ' to ensure that the situation model is an accurate representation of the text. The need to revise may not always be triggered by an explicitly stated concept (such as ' $d o g$ ' in the previous example). A continuation that invites an inference (e.g., 'The bigger animal barked loudly...') would also require readers to revise the earlier inference that the animal was a 'cat.' We have called this process inferential revision, and a deeper understanding of how individual differences in working memory affect this process is the main goal of the present study.

A number of different paradigms show that while readers easily incorporate new information into their situation model (e.g., Rapp \& Kendeou, 2007; Rapp \& Taylor, 2004), they do not always successfully revise their mental representation when new information contradicts previously stated information (e.g., Guéraud, Harmon, \& Peracchi, 2005; O’Brien, et al., 1998; Rapp \& Kendeou, 2007, 2009). In a classic example, O'Brien et al. (1998) found that participants took longer to read a sentence regarding a person's behavior when that behavior contradicted earlier information (e.g., reading 'Mary ordered a

\footnotetext{
${ }^{1}$ Importantly, the example provided here does not exactly represent a real inconsistency (the concept ' $d o g$ ' is plausible in the context of 'bigger animal'), but an alternative concept that differ from the most probable inference ('cat'). This process has been called inference alteration (e.g., Radvansky \& Copeland, 2004)
}

cheeseburger and fries' after 'Mary, a health nut, had been a strict vegetarian for 10 years'). This finding indicates that although participants detected the inconsistency between the character's behavior and earlier information, they experienced difficulty integrating the new information into their mental representation. This comprehension difficulty was reduced, but still evident, in a qualified condition that provided an additional explanation for the character's behavior encouraging a revision of the situation model ('Nevertheless, Mary never stuck to her diet when she dined out with her friends'). If participants had successfully revised their situation model to incorporate this qualification, there would have been no comprehension difficulty. Thus, when new information is inconsistent with prior parts of the text, successful understanding requires the revision of the situation model.

One reason for a failure to revise the situation model is that readers have problems replacing outdated information (Kendeou, Smith, \& O'Brien, 2013; O’Brien, Cook, \& Guéraud, 2010). The Knowledge Revision Comprehension framework (KReC; Kendeou \& O’Brien, 2014) proposes that once information is retrieved from long-term memory, the activation of the new information competes with the nolonger-relevant information, drawing activation away from the now-outdated information. Importantly, if the activation of the outdated information is not sufficiently reduced by the competition mechanism, this information may interfere with the new information, making difficult the revision of the situation model. Empirical support for this comes from studies of children and adults with poor text comprehension. These studies show a relationship between poor comprehension and difficulties with working memory, a key cognitive resource that supports the general processes involved in the construction of the situation model. Critically, these working memory difficulties are associated with deficient suppression or inhibitory control over the contents of working memory (Cain, 2006; Carretti, Corndoldi, De Beni, \& Palladino, 2004; Pimperton $\&$ Nation, 2010). For example, Carretti et al. (2004) found that good comprehenders had higher working memory capacity than poor comprehenders and were also better at recalling words in a categorization task: they made fewer intrusion errors (words that had been categorized but were not listed as final words and so should not be recalled). These findings suggest that the relationship between poor reading comprehension and poor working memory may be related to difficulties that poor comprehenders have with inhibiting irrelevant information.

These studies linking poor comprehenders' working memory capacity to problems with inhibition also fit well with Gernsbacher's model of text comprehension: the StructureBuilding framework (Gernsbacher, 1990, 1997). This framework proposes that readers with low working memory capacity have problems with text comprehension because of difficulties with suppressing irrelevant information. As a result, 
they generate new substructures rather than integrating new information into the situation model and therefore produce a less coherent situation model than good comprehenders (e.g., Gernsbacher \& Faust, 1991; Gernsbacher, Varner, \& Faust, 1990). This body of work provides both empirical and theoretical support for the proposal that readers with good working memory may be better able to revise their situation model than readers with poor working memory, because they are more efficient at inhibiting no-longer-relevant information, an essential process to construct an accurate and coherent situation model.

Surprisingly, there are very few studies investigating how individual differences in working memory are associated with the process of inferential revision. Indirect evidence for such an association comes from a study by Dutke and von Hecker (2011). They investigated how working memory capacity affects the process of revising the situation model when ambiguous information is read. They presented narrative texts about the social relations between protagonists to adult readers with high or low working memory span. High-span readers were better able than low-span readers to inhibit an earlier representation (e.g., 'Franco and Salvatore relied on each other') that was incompatible with new information (e.g., 'Franco found Salvatore's anxieties very annoying'). This suggests that an individual's memory capacity is related to their ability to revise a situation model. However, although Dutke and von Hecker's (2011) study focused on the structure of social relations described in the text to investigate inferential revision, they did not use moment-bymoment processing measures to study revision during the construction of the situation model. Moreover, in a separate study, Dutke and colleagues found evidence indicating that some of the situation model revision took place after reading the text (Dutke, Baadte, Hähnel, von Hecker, \& Rinck, 2010), which leaves open the question of whether the revision process may occur when reading the text (that is online) under certain circumstances.

From our point of view, it is important to understand the time course and accuracy with which readers revise inferential information in their situation model, to elucidate reading comprehension problems at a high level of processing. Thus, the present study aims to investigate the inferential revision process in two important ways. First, we developed a paradigm that enabled us to dissociate the two key components of comprehension monitoring described earlier: the detection of a mismatch (evaluation process) and the updating of no longer relevant information (revision process) at an inferential processing level. Second, we examined how individual differences in working memory were associated with the process of revising the situation model. To explore these issues, we recorded reading times and electrophysiological brain activity during online reading.

\section{Behavioral measure}

Reading times Reading times are an established way to assess processing difficulty. Readers typically take longer to read a sentence if they detect a mismatch between the text and what they have read previously (O'Brien et al., 1998), and they also take longer to read critical sentences when inferential processing is required (McKoon \& Ratcliff, 1992). Our texts contained a sentence that either prompted readers to make a revision or not to the current situation model. Reading times for this sentence were compared across these conditions to determine whether participants had successfully evaluated the new information against the existing situation model. The reading times did not enable us to establish whether or not participants had actually revised their situation model and replaced the nowincorrect inference with the new correct inference. Because event-related potentials (ERPs) are a robust means to study the precise time course of many cognitive processes, we examined distinct ERP components to a subsequent critical word in the text to investigate the revision process.

\section{ERP measures}

P3a and P3b subcomponents A relevant theoretical framework for the purposes of the present experiment is the contextupdating theory (Polich, 2003, 2007). This framework distinguishes two subcomponents of the P300: a central-frontal positivity, or 'P3a' (e.g., Debener, Makeig, Delorme, \& Engel, 2005), which is evident when incoming information is evaluated as new or different with respect the current representation demanding attentional control; and a temporo-parietal positivity, or 'P3b' (e.g., Hartikainen \& Knight, 2003), which has been found when the context of the incoming stimulus involves updating by memory processes. Generally, the P3a is assumed to reflect mechanisms of attentional orientation driven by a target or novel stimulus (see Friedman, Cycowicz, \& Gaeta, 2001, for review), whereas the P3b is related to processing capacity, being affected by the allocation of cognitive resources, the relevance of the stimulus to the task, and the probability of the stimulus (e.g., Kok, 2001). These findings suggest the existence of a brain circuit encompassing a) a topdown, stimulus-driven process that takes place in frontal areas (P3a) and b) a bottom-up, memory-driven process, which is guided by updating operations and occurs in parietal areas (P3b; see Polich, 2003). Accordingly, we used the P3a as an additional index of the detection of mismatches (evaluation process) and the $\mathrm{P} 3 \mathrm{~b}$ as an index of the updating of nolonger-relevant information (revision process).

Moreover, some studies have demonstrated a selective relationship between the reduction of the P3b amplitude and poor execution in several capacities, such as comprehension monitoring (Getzmann \& Falkestein, 2011) and working 
memory capacity (Evans, Selinger, \& Pollak, 2011). In support of this distinction, and of relevance to the current study, is work by Getzmann and Falkestein (2011). They compared younger (19-25 years) and older (54-64 years) adults' performance on a comprehension monitoring task in which participants had to respond according to the stock price of a specific company, while ignoring other prices and beep sounds. Interestingly, participants did not show significant differences in the behavioral results (accuracy and reading times), but electrophysiological differences emerged. Specifically, the older adults manifested an increased right-frontal P3a (only in highperforming older adults) and a reduced parietal $\mathrm{P} 3 \mathrm{~b}$ relative to the younger adults. The authors interpreted the $\mathrm{P} 3$ a result as an age-related compensatory mechanism and the $\mathrm{P} 3 \mathrm{~b}$ result as an effect of age-related decline in spoken-language comprehension. These data signal that the P300 subcomponents may reflect individual differences in language comprehension.

N400 component Another ERP of interest is the N400, which is an index of the ease with which the meaning of a word can be integrated into the current situation model (see Kutas \& Federmeier, 2009, 2011). The amplitude of the N400 is reduced when there is a good fit between the word being processed and the context, in comparison to a poorly fitting word. For example, Kuperberg, Paczynski, and Ditman (2011) demonstrated a N400 for words causally unrelated to an inference supported by the text (e.g., 'Jill's skin always tanned well. She always put on sunscreen. She had sunburn on Monday.') compared to causally related words (e.g., 'Jill had very fair skin. She forgot to put sunscreen on. She had sunburn on Monday.'). However, although there have been several electrophysiological studies demonstrating a relation between working memory and inference making (e.g., St. George, Mannes, \& Hoffman, 1997) and in evaluation of coherence breaks (e.g., Virtue, Haberman, Clancy, Parrish, \& Jung-Beeman, 2006), no study to date has investigated the relationship between working memory and the revision of the situation model using ERPs. Therefore, a second aim of the present study was to explore if these ERP components (P3a, P3b, and N400) reflected individual differences in working memory associated with the construction of the situation model.

\section{The current study}

To address our aims, we developed the situation model revision task (see Table 1). Participants read short texts in which Sentences 1 through 3 provided an introduction for which at least two different concepts could be inferred by means of the generation of knowledge-based elaborative inferences (McKoon \& Ratcliff, 1980). Both concepts were plausible, but one was considered more likely (e.g., 'guitar') by independent judges (see Table 1). There were three versions of the subsequent Sentence 4: a neutral condition, which did not refer directly or indirectly to either concept; a no-revise condition, which mentioned a property consistent with either concept (e.g., '...beautiful curved body'); and a revise condition, which referred to a property that was consistent with only the less likely concept (e.g., '...matching bow'). This latter condition should prompt readers to revise the situation model to ensure good comprehension. Reading times were measured for this sentence. The final word in Sentence 5 was always inconsistent with the concept supported in the introduction but consistent with the concept supported in the revise condition (e.g., 'violin'). This word was called the disambiguating word, and ERPs were recorded here.

Our predictions were as follows. First, in relation to the behavioral data, if readers generate and encode the inference supported by the introduction ('guitar'), then they will show longer reading times for Sentence 4 in the revise condition ('matching bow') compared to the neutral ('national concert hall') and no revise ('beautiful curved body') conditions. This effect would signal the ability to detect a mismatch (evaluation process) when new information does not match the current situation model (e.g., Bohn-Gettler, Rapp, Van den Broek, Kendeou, \& White, 2011). As noted, longer reading times do not enable us to establish if readers are able to replace the incorrect inference with the alternative inference when prompted by Sentence 4 in the revise condition. The ERP data, registered for the disambiguating word of Sentence 5, help us to understand whether readers not only detect a mismatch when reading Sentence 4 in the revise condition, but also whether they successfully revise their situation model, as detailed below.

In line with Polich $(2003,2007)$, the P3a subcomponent shows if a word is evaluated as new or different with respect to the current mental representation. Thus, if readers activate the alternative inference when reading Sentence 4 in the revise condition, then they will exhibit a reduction of the P3a to the disambiguating word ('violin') in the revise condition ('matching bow') compared with the neutral ('national concert hall') and no revise ('beautiful curved body') conditions. This pattern would signal not only the activation of the new inference when reading Sentence 4 in the revise condition but also the mismatch detection for Sentence 5 in the neutral and no revise conditions. The $\mathrm{P} 3 \mathrm{~b}$ subcomponent indicates if a word prompts a revision of the situation model. Therefore, similar to the $\mathrm{P} 3 \mathrm{a}$, if readers are able to update the alternative inference and draw activation away from the previous incorrect inference when reading Sentence 4 in the revise condition, they will show a reduction of the $\mathrm{P} 3 \mathrm{~b}$ to the disambiguating word in the revise condition compared with the neutral and no revise conditions. This effect would demonstrate that readers not only activate the new inference when reading Sentence 4 in the revise condition but they are also able to revise their mental representation. Finally, the N400 component is an 
Table 1 Example of text used in the situation model revision task

Dan was a gypsy who had played flamenco since childhood.

Introduction (bias guitar)

Now he is a popular musician who plays all over the world.

Today, he is giving a recital of his favorite works.

The concert takes place at the prestigious national concert hall.

Neutral

His instrument is made of maple wood, with a beautiful curved body.

No revise

His instrument is made of maple wood, with a matching bow.

Revise

The public was delighted to hear Dan playing the violin.

ERP sentence

In the recital, Dan played his favorite works.

Comprehension sentence

Note. Participants saw the text in the neutral, no revise, or revise condition. The word in bold in the ERP sentence was the disambiguating word

index of the ease with which information can be integrated into a reader's situation model. If readers integrate the alternative inference when reading Sentence 4 in the revise condition, then they will demonstrate a reduction of the N400 to the disambiguating word in the revise condition compared with the neutral and no revise conditions. This result would indicate that readers are able to integrate the new inference into their situation model when reading Sentence 4 in the revise condition.

Furthermore, if readers with low working memory are less able to evaluate their comprehension and revise their situation model than readers with high working memory, they will not manifest significant differences between conditions in the disambiguating word compared with high working memory readers, who will. However, because to our knowledge this is the first ERP study investigating individual differences in the inferential revision process, we did not make specific hypotheses about the electrophysiological components for high and low working memory readers. Importantly, our paradigm enables us to combine behavioral and electrophysiological data to understand better how working memory relates to a reader's ability to evaluate and inferentially revise their situation model.

\section{Method}

\section{Participants}

Seventy-seven people living in the city of Granada (Spain), with a mean age of 22.5 years (range: 18-37 years) were recruited by an Internet advertisement to participate for payment. All were native English speakers and gave their consent to participate in the experiment. After they performed the two memory tasks (memory updating and reading span), only participants with extreme working memory scores (see below) were invited to complete the situation model revision task.

\section{Materials}

Memory updating task We developed an English version of Carretti, Belacchi, and Cornoldi's (2010) memory updating task. Participants read lists of words, one word at a time. The number of words in the lists increased from 2 to 12 as the trials progressed. The words were concrete nouns referring to objects of different sizes (large or small, e.g., 'ship' or 'pea'). The task was to recall the smallest object or objects in the list, according to their physical size. The number of words to be recalled was stated before each list and increased from one to five, with a fixed presentation order. Participants were required to a) activate and maintain each new word in working memory to compare its size with previously presented words, b) maintain activation of the smallest objects in the specified set size, and c) inhibit any previously activated words that no longer meet the criteria (i.e., to inhibit a largesize object when they heard the name of a smaller object). Therefore, the recall set of words had to be constantly revised as new words were presented. All participants completed all trials.

Reading span task We used a version of Daneman and Carpenter's (1980) reading span task. Participants read sets of sentences presented one by one and were required to recall the last word of each sentence, at the end of each set of sentences. The order of recall was not important, but participants could not start with the last word of the last sentence. There were five levels, increasing in difficulty from two to six sentences. A level was considered correct if participants recalled correctly each last word of at least three out of five (maximum) sets of sentences.

The score for both memory tasks was the total number of words correctly recalled minus the total number of words incorrectly recalled (intrusions). These scores were used to classify participants into the high and low working memory groups, using the criterion of being above or below (respectively) the mean of the total score in both working memory tasks (see scores below).

Situation model revision task We constructed 93 (3 practice, 90 experimental) five-sentence narrative texts, some modified from texts used by Lorsbach, Katz, and Cupak (1998). An example is shown in Table 1 (see the full set of materials in Appendix A). The first three sentences supported a specific 
inference to be made (e.g., 'guitar'). There were three versions of Sentence 4: the neutral condition, which did not refer back to either the supported or the alternative inference and, therefore, was neither consistent nor inconsistent with the introduction; the no revise condition, which was consistent with the inference primed by the introduction; and the revise condition, which prompted readers to revise their situation model so that only the alternative inference was encoded, rather than the inference supported by the introduction. Reading times were the dependent variable for this sentence. Sentence 5 concluded with a disambiguating word (e.g., 'violin'), which was always incongruent with the inference supported by the introduction and congruent with the inference supported by Sentence 4 in the revise condition. Consequently, the disambiguating word was unexpected in the neutral and no revise conditions, and expected in the revise condition. At the end of the text, a comprehension sentence requiring a true or false judgment was included to encourage participants to read for meaning.

A norming study provided empirical confirmation of concept preferences in our situation model revision task. Twentytwo participants $(M=22.7$ years old; range: $18-55)$ read the introduction of each text (Sentences 1-3) and were then presented with a single word. Their task was to decide (yes/no) if the word fitted with the sense of the story. The word was either the target concept, which was most strongly supported by the introduction (e.g., 'guitar'), the alternative concept (e.g., 'violin'), or a nonstory concept (e.g., 'poker'). Results of a one-way ANOVA performed on the percentage of accuracy showed a main effect of concept type, $F(2,42)=92.92, p<$ $.001, p \eta^{2}=.82$, because participants were more likely to correctly accept the target concept $(M=83.95, S D=7.71)$ and to correctly reject the nonstory concept $(M=88.95, S D=7.24)$ than to accept the alternative concept $(M=50.43, S D=12.43)$. Furthermore, when participants did accept the alternative concept, they took longer to do so $(M=2079 \mathrm{~ms})$ compared with response times to the target concept $(M=1612 \mathrm{~ms}): t(21)=$ $3.72, p<.001$. $^{2}$ This difference suggests that, after reading the introduction, the target concept was significantly more likely to be activated than the alternative concept, as intended. It is important to acknowledge that there was variability in the extent to which our 90 texts constrained the activation of the target concept in the introduction. A second norming study with a two-alternative forced choice task confirmed that the two critical concepts were both supported by Sentence 4 (e.g., 'guitar' for the no revise, and 'violin' for the revise). Fourteen participants $(M=20.9$ years old; range: $18-26)$ read the introduction, followed by one of the two versions of Sentence 4 . They were instructed to mark the concept that the text was

\footnotetext{
${ }^{2}$ Because the rejection search process for words that did not fit the meaning is different from the confirmatory search process for words that fit, we did not include the correct rejection of the nonstory concept in the response time analysis.
}

about. Seven participants completed each version of each text. In the final study, we included only texts for which the appropriate word was selected in both versions by a minimum of five participants. The sample used in the norming studies did not take part in the main study.

The word frequency for each of the two critical concepts was examined using the Word Frequency Guide database (Zeno, Ivens, Millard, \& Duvvuri, 1995) and did not differ $(M \mathrm{~s}=56.58$ and 47.18, for the no revise and revise concepts, respectively), $t(89)=0.27, p=.79$. The word length of Sentence 4 did not differ between conditions $(M \mathrm{~s}=11.70,11.46$, and 11.81, for the neutral, no revise, and revise conditions, respectively), $F(2,178)=1.74, p=.18$. Finally, although we tried to minimize nonmanipulated differences between our conditions, the structure for Sentence 4 varied across conditions.

\section{Procedure}

Materials were administered in two sessions. The first session took approximately 30 minutes and included the two memory tasks. The memory updating task was administered first. Before each word list, participants were informed of the number of words in the list and how many objects to recall. Each word was presented on a computer screen for 2 seconds. A question mark prompted recall, and the participant said their response out loud. A practice trial preceded the experimental trials. The reading span task was completed next. Participants were instructed to recall the last word of each sentence and, before each block, they were informed of the number of sentences (and words to recall) in the trial. Participants read each sentence at their own pace. At the end of the trial, a white screen appeared, and participants said aloud the words that they could remember. A practice trial preceded the experimental trials.

Before the second session, the scores of both working memory tasks were used to divide participants into two groups: 18 low and 18 high working memory readers. The mean number of words recalled for the low memory group was $21.11(S D=2.74$; range $=16-24)$ in the memory updating task and $29.50(S D=8.03$; range $=16-44)$ in the reading span task; and for the high memory group was $26.39(S D=1.50$; range $=24-29)$ in the memory updating task and $68.39(S D=$ 12.10 ; range $=47-86)$ in the reading span task. $T$-tests confirmed significant group differences in both memory tasks: updating, $t(34)=7.17, p<.001$; and reading span, $t(34)=$ $11.36, p<.001$.

In the second session, participants completed the situation model revision task. This session took approximately 90 minutes and included only participants with low and high working memory. First, we placed the electrode cap onto the participant's head to record the EEG. Each trial started with a fixation point ('+') that remained on the screen until the participant pressed the ' $\mathrm{B}$ ' key on the keyboard to present the first 
sentence. Sentences 1-4 were presented one sentence at a time, and participants were instructed to read each sentence at their own pace, pressing the space bar to display the next sentence. The reading time of Sentence 4 (neutral vs. no revise vs. revise) was recorded. Immediately after, Sentence 5 was presented word by word with a fixed duration of $300 \mathrm{~ms}$ per word. In addition, there was a delay of $700 \mathrm{~ms}$ after the disambiguating word to ensure that the electrophysiological activities of the ERPs were registered. To prevent excessive noise in the electrophysiological data, we asked participants to try not to blink during the presentation of Sentence 5. Finally, participants were presented with a true/false comprehension sentence. This sentence always referred to information in the introduction (equally distributed across Sentences 1-3). Participants pressed the designated true or false key to respond.

Each of 90 experimental texts was presented to each participant only once in one of the three conditions, counterbalanced across participants. The task was administered in three blocks, keeping the same proportion (10 texts) in each condition per block. The same number of participants completed each condition, and the presentation of texts was randomized within block. A practice of three trials ensured that instructions were understood.

\section{Apparatus}

All tasks were presented by the E-prime software (Schneider, Eschman, \& Zuccolotto, 2002), administered on a 19 in. CRT video monitor (refresh rate $=75 \mathrm{~Hz}$ ). For the situation model revision task, scalp voltages were recorded from a SynAmps2 64 channels Quik-Cap, plugged into a Neuroscan SynAmps RT amplifier. The electrical signal was amplified with a 1$30 \mathrm{~Hz}$ band-pass filter and a continuous sample rate of $250 \mathrm{~Hz}$. Ocular movements and blinks were also collected by two pairs of channels: a) the vertical electrooculogram situated in the left eye of the participant, with one electrode supra and another infraorbitally to measure blink artifact; b) the horizontal electrooculogram placed in the external canthi, with one electrode on the left and another on the right side to register eye movements. Impedances were kept below $5 \mathrm{k} \Omega$. Both blinks and ocular movements were corrected. In addition, trials with artifacts were rejected $(3.12 \%)$ and, in those cases where electrodes had a high level of artifacts $(>1 \%)$, these were substituted by the average value of the group of nearest electrodes. Epochs with an interval between -200 and $800 \mathrm{~ms}$ with respect to the presentation of the target word (disambiguating word) were averaged and analyzed. Baseline correction was applied using the average EEG activity in the $200 \mathrm{~ms}$ preceding the onset of the target as a reference signal value. Separate ERPs averages were developed for each condition for each participant. Individual averages were rereferenced off-line to the average of left and right mastoids. Six regions of interest (ROI) were extracted from the 64 channels (see Figure 1), keeping the criteria of 1) symmetry between hemispheres and 2) same number of electrodes (five sites $)^{3}$ : left frontal, or LF (F1, F3, F5, FC3, and FC5); right frontal, or RF (F2, F4, F6, FC4, and FC6); central, or C (C1, $\mathrm{C} 2, \mathrm{CZ}, \mathrm{FCZ}$, and CPZ); left parietal, or LP (P1, P3, P5, CP3, and $\mathrm{CP} 5)$; right parietal, or $\mathrm{RP}(\mathrm{P} 2, \mathrm{P} 4, \mathrm{P} 6, \mathrm{CP} 4$, and $\mathrm{CP} 6)$; and occipital, or $\mathrm{O}(\mathrm{O} 1, \mathrm{O} 2, \mathrm{POZ}, \mathrm{PO} 3$, and PO4).

\section{Statistical analyses}

We report statistical analyses of 36 participants for all trials. ${ }^{4}$ Working memory group was a between-subjects factor in all analyses. The behavioral analysis of the situation model revision task was conducted on reading times (milliseconds) per sentence. In the ERP analyses, the critical time windows were predefined by visual inspection. In this way, the mean amplitude was calculated in the window of 220-300 ms (P3a and $\mathrm{P} 3 \mathrm{~b}$ ) and the window of 300-550 ms (N400) after the disambiguating word onset (see Figure 2). Outlier amplitude data per condition, group and ROI was detected by the BoxWhisker plot, and replaced by the mean for both the P300 $(3.70 \%)$ and the N400 (2.47\%).

\section{Results}

\section{Behavioral analysis (Sentence 4)}

Reading times To understand if readers generated the inference in the introduction and then evaluated their comprehension by detecting a mismatch in the revise condition, we performed a mixed model ANOVA with working memory group (high vs. low) and condition (neutral vs. no revise vs. revise) on the reading time of Sentence 4 . There was only a main effect of condition, $F(2,68)=11.27, p<.001, p \eta^{2}=.25$, where the revise condition resulted in longer reading times $(M=3076 \mathrm{~ms})$ than the other two conditions: neutral $(M=$ $2801 \mathrm{~ms})$, and no revise $(M=2714 \mathrm{~ms})$. $T$-tests revealed that the revise condition significantly differed from the neutral, $t(35)=3.01, p=.005$, and the no revise, $t(35)=4.21, p<$ .001 , conditions. The comparison between the neutral and the no revise condition was not significant, $t(35)=1.43, p=.17$. The memory group effect, $F(1,34)=1.82, p=.19$, and the

\footnotetext{
${ }^{3}$ Because the magnitude of the components involved in the inferential revision process is still unknown, our regions of interest were selected taking into account a good representation of the different parts of the scalp.

${ }^{4}$ Comprehension sentences always referred to Sentences 1-3, and so they did not affect either Sentence 4 (reading times) or the disambiguating word (ERPs). $T$-test comparison on reading times confirmed no differences between the sample without incorrect responses and the whole sample, $t(35)=0.07, p=.95$.
} 
Fig. 1 The six regions of interest (ROI): left frontal (LF); right frontal (RF); central (C); left parietal (LP); right parietal (RP); and occipital $(\mathrm{O})$

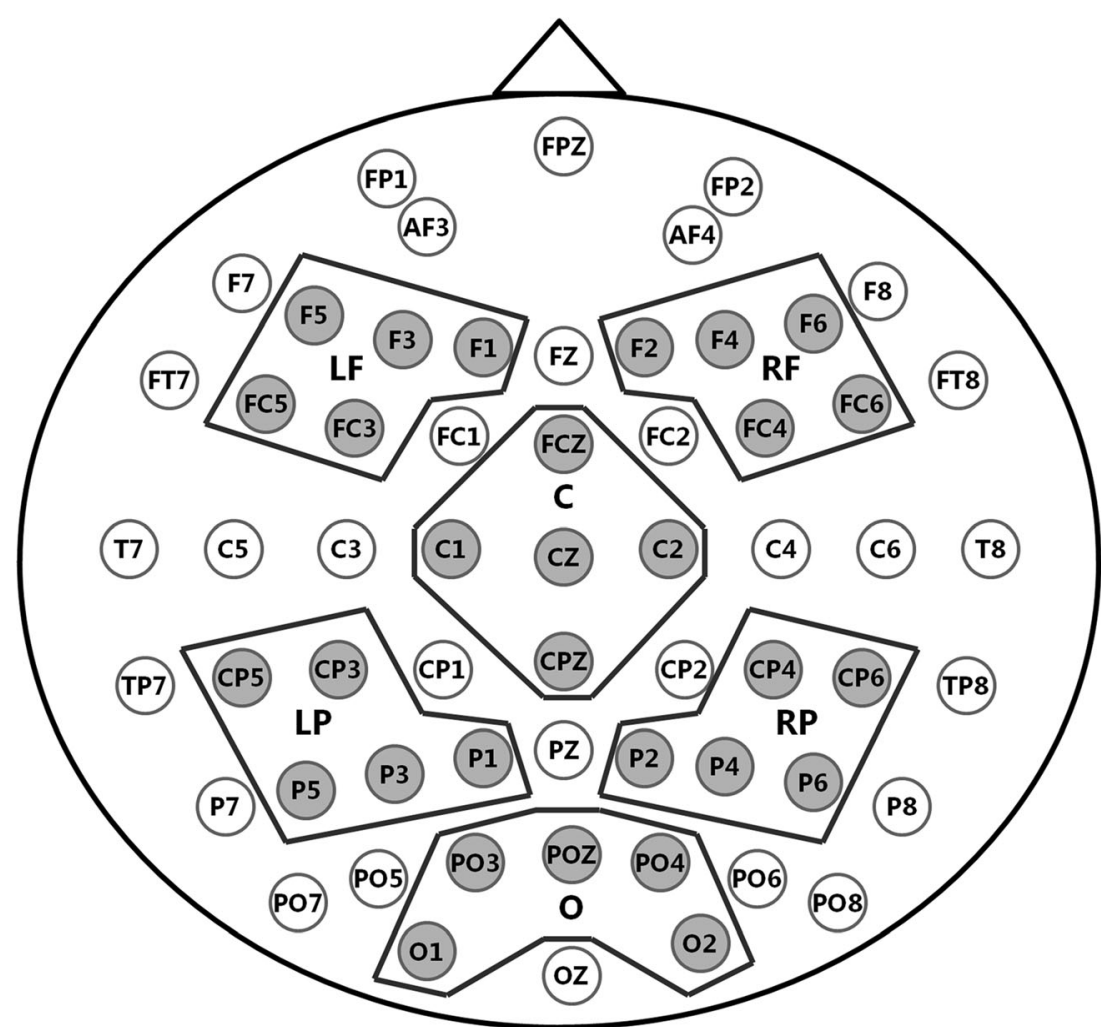

memory group $\times$ condition interaction, $F(2,68)=1.82, p=$ .17 , were not significant (see Table 2 for means). ${ }^{5}$

\section{ERP analysis (disambiguating word)}

First, in order to see if both subcomponents of the P300 (P3a and P3b) could be distinguished in our data, we carried out a mixed model ANOVA with working memory group, condition and ROI on the mean amplitude data in the time window of 220-300 ms, dividing ROI in central-frontal (C, LF, and $\mathrm{RF}$ ) and posterior (LP, RP, and O) regions. The analysis showed a tendency toward a larger positivity in the high memory group compared to the low memory group, $F(1,34)=$ $3.19, p=.08, p \eta^{2}=.09$. There was a significant main effect of condition, $F(2,68)=6.17, p<.01, p \eta^{2}=.15$, with more positive amplitude in the neutral and no revise conditions compared to the revise condition. There was also a main effect of ROI, $F(1,34)=174.67, p<.001, p \eta^{2}=.84$, because the central-frontal regions were significantly more positive than

\footnotetext{
5 To investigate whether the behavioral result was significant across texts, we conducted a linear mixed effect model with reading times, using condition as a fixed effect and participants and texts as random effects. In addition, to control the variability caused by the number of words, we also included sentence length as a random slope in the text factor. The result demonstrated the same significant main effect of condition found in the ANOVA, $F(2)=52.54, p<.001$. The $p$ value and $d f$ of the fixed effect were extracted using the ANOVA function of the lmerTest $\mathrm{R}$ package, version 2.0-11 (Kuznetsova, Brockhoff, Christensen, 2012).
}

the posterior regions. Critically, although no two-way interaction reached significance (all $p \mathrm{~s}>.28$ ), the three-way interaction was significant, $F(2,68)=7.26, p<.01, p \eta^{2}=.18$. Therefore, we conducted separate analyses for the P3a (C, LF, and RF) and the P3b (LP, RP, and O) subcomponents.

P3a analysis Our aim was to see if readers generated the alternative inference on reading Sentence 4 in the revise condition and then, evaluated the disambiguating word as already activated. To do this, we performed a mixed model ANOVA with working memory group, condition, and the three $\mathrm{ROI}^{6}$ associated with the P3a (LF, RF, and C) on the mean amplitude data (for the disambiguating word) in the time window of $220-300 \mathrm{~ms}$. As before, there was a tendency toward a larger positivity in the high memory group compared to the low memory group, $F(1,34)=3.36, p=.08, p \eta^{2}=.09$. The main effect of condition was significant, $F(2,68)=3.87, p=.03$, $p \eta^{2}=.10$, where, as predicted, the amplitude for the disambiguating word following the neutral and no revise conditions of Sentence 4 was larger $(M=2.51, S D=1.25$ and $M=2.54$, $S D=1.17$, respectively) than that found in the revise condition $(M=2.02, S D=1.58)$. There was also a main effect of ROI, $F(2,68)=5.83, p=.006, p \eta^{2}=.15$, with larger positivity in the $\mathrm{C}$ and $\mathrm{RF}$ regions than in the LF region. No interactions were significant (all $p \mathrm{~s}>.35$ ).

\footnotetext{
${ }^{6}$ ROI $p$ values are based in a Greenhouse-Geisser correction.
} 
Fig. 2 Graphical representation of the mean amplitude (in microvolts) for the P300 (pale gray column) and the N400 (dark gray column) components, divided by working memory group, condition and ROI
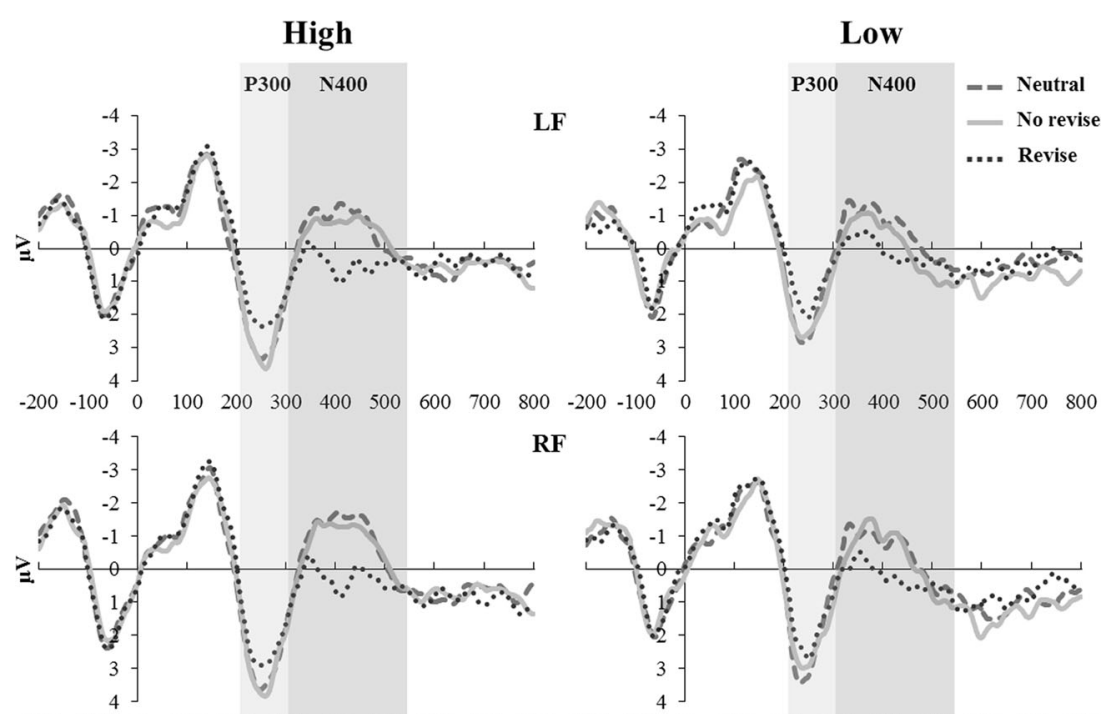

$\begin{array}{llllllllllllllllllllll}-200 & -100 & 0 & 100 & 200 & 300 & 400 & 500 & 600 & 700 & 800 & -200 & -100 & 0 & 100 & 200 & 300 & 400 & 500 & 600 & 700 & 800\end{array}$

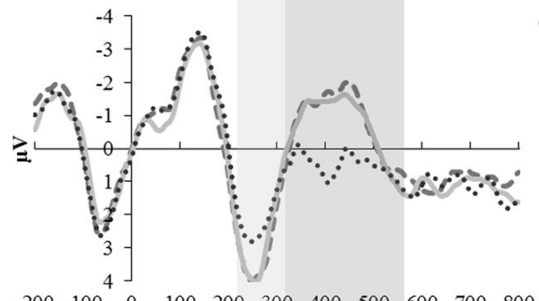

C

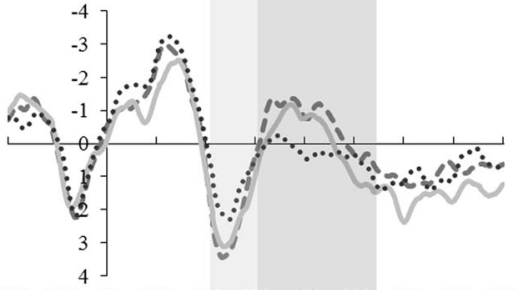

$\begin{array}{lllllllllll}-200 & -100 & 0 & 100 & 200 & 300 & 400 & 500 & 600 & 700 & 800\end{array}$

LP $\quad-4$

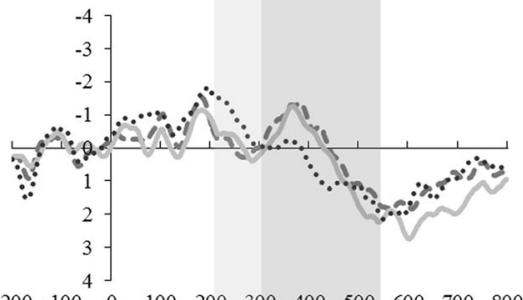

RP

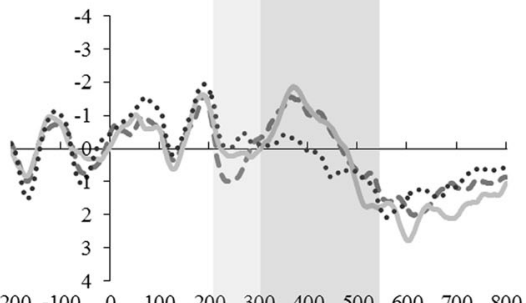

$\begin{array}{cccccccccc}-200 & -100 & 100 & 200 & 300 & 400 & 500 & 600 & 700 & 800\end{array}$

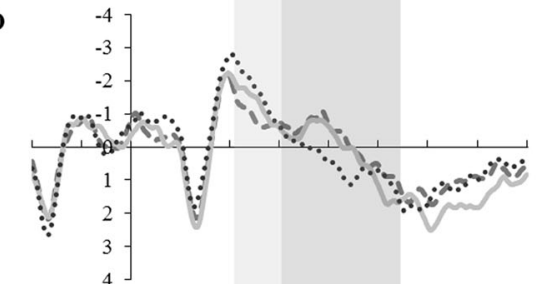

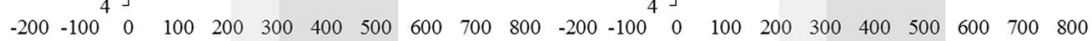

P3b analysis To determine if readers revised their mental representation reducing activation from the previous incorrect inference on reading Sentence 4 in the revise condition, we performed a third mixed model ANOVA with working memory group, condition, and the three
ROI related to the $\mathrm{P} 3 \mathrm{~b}$ (RP, LP, and $\mathrm{O}$ ) on the mean amplitude data (for the disambiguating word) in the same temporal window. The main effect of memory group did not reach significance, $F(1,34)=1.00, p=$ .33. There was a significant effect of condition, $F(2,68)$ 
Table 2 Reading time means for Sentence 4 of the situation model revision task, divided by working memory group and condition

\begin{tabular}{lllll}
\hline & Condition & $M$ & $S D$ & Range \\
\hline High & Neutral & 2675 & 891 & $1535-4954$ \\
& No revise & 2631 & 763 & $1588-4149$ \\
& Revise & 2845 & 533 & $2003-3837$ \\
& & & & \\
Low & Neutral & 2926 & 651 & $1751-4406$ \\
& No revise & 2798 & 575 & $1685-3963$ \\
& Revise & 3306 & 762 & $1741-4647$ \\
\hline
\end{tabular}

$=7.42, p=.002, p \eta^{2}=.18$, because as predicted the amplitude in the neutral and no revise conditions was more positive than in the revise condition. There was also a main effect of ROI, $F(2,68)=72.11, p<.001$, $p \eta^{2}=.68$, because the two parietal regions (LP and RP) were significantly more positive than the $\mathrm{O}$ region. In addition, there was a significant two-way interaction between memory group and condition, $F(2,68)=3.79, p$ $=.03, p \eta^{2}=.10$. No other interactions reached significance (all $p \mathrm{~s}>.10)$.

To identify the locus of the interaction between memory group and condition (see Figure 3), planned comparisons between conditions were carried out for each group separately, with a Bonferroni correction setting the alpha at .008. For the high memory group, significant differences between the revise condition and both the neutral and no revise conditions were apparent, $t(17)=4.02, p<.001$, and $t(17)=3.13, p=.007$, respectively; whereas the neutral and no revise conditions did not differ $t(17)=1.26, p=.22$. A different pattern was apparent for the low memory group: none of the contrasts reached significance (all $p s>.44)$.

N400 analysis To see if readers integrated the alternative inference on reading Sentence 4 in the revise condition, we performed a final mixed model ANOVA with working memory group, condition and the six ROI on the mean amplitude data (for the disambiguating word) in the time window of 300-550 ms. The main effect of memory group did not reach significance, $F(1,34)=0.91, p=.35$. There was a main effect of condition, $F(2,68)=21.84, p<.001, p \eta^{2}=.39$, because as predicted the amplitude in the neutral and no revise conditions was more negative than in the revise condition. There was also a tendency toward a main effect of ROI, $F(5,170)=2.65, p=$ $.07, p \eta^{2}=.07$, with less negativity in the LP region. In addition, there were two significant interactions. The first two-way interaction between condition and ROI, $F(10,340)=3.94, p=$ $.001, p \eta^{2}=.10$, arose because the neutral and the no revise conditions were more negative than the revise condition, particularly in the RP region, $t(35)=7.23, p<.001$, and $t(35)=$ $6.60, p<.001$, respectively. The second two-way interaction

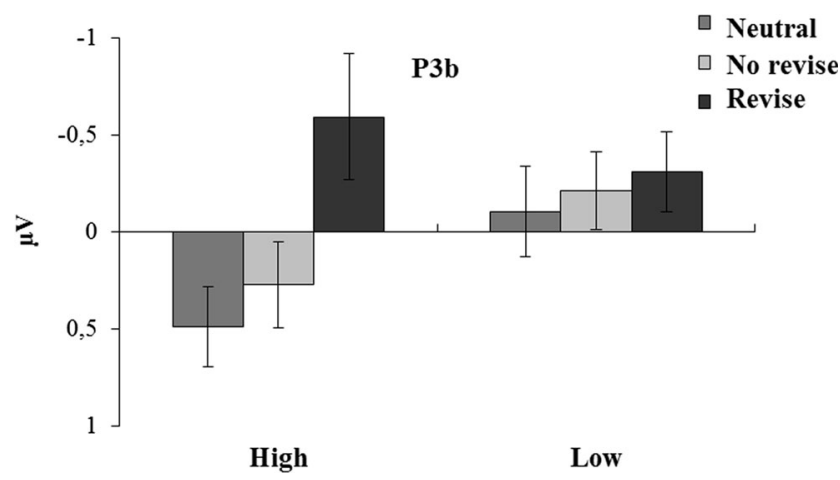

Fig. 3 Mean amplitude of the P3b subcomponent for the disambiguating word of the situation model revision task, divided by working memory group and condition

between memory group and condition, $F(2,68)=3.85, p=$ $.03, p \eta^{2}=.10,^{7}$ is of specific interest to our understanding of the integration process and therefore, is discussed in detail below. A further two-way interaction between memory group and ROI showed a tendency toward significance, $F(5,170)=$ $2.08, p=.07, p \eta^{2}=.06$, with larger negativity for the high compared to the low working memory group in the posterior regions (LP, RP, and O). Finally, the three-way interaction was not significant, $F(10,340)=1.29, p=.23$.

The two-way interaction between memory group and condition (see Figure 4) was explored further to understand the integration process. Planned comparisons between conditions for each memory group separately were used to identify the locus of this interaction, again with a Bonferroni correction setting the alpha at .008 . Only the high memory group showed more negative amplitude in the no revise condition compared to the revise condition. Specifically, this group showed larger negativity in the neutral condition, $t(17)=6.80, p<.001$, and the no revise condition, $t(17)=6.02, p<.001$, compared to the revise condition. The neutral and the no revise conditions did not differ, $t(17)=0.19, p=.85$. In contrast, the low memory group showed larger negativity in the neutral compared with the revise condition, $t(17)=3.44, p=.003$, but there was no difference between the no revise and the revise condition, $t(17)=1.46, p=.16$; nor between the neutral and the no revise condition, $t(17)=1.49, p=.15$.

\footnotetext{
${ }^{7}$ To explore whether the effect of working memory in the P3b and N400 was linear, we conducted separate linear mixed effect models for each component, using working memory (continuous scores) and condition as fixed effects, and participants and texts as random effects. These models shown the same significant two-way interaction between working memory and condition as found in the ANOVAs for both the P3b, $F(3)=5.67$, $p=.001$, and the N400, $F(3)=3.79, p=.01$. However, because we previously selected participants with high or low working memory, working memory was not a real continuous variable and therefore these results must be interpreted with caution.
} 


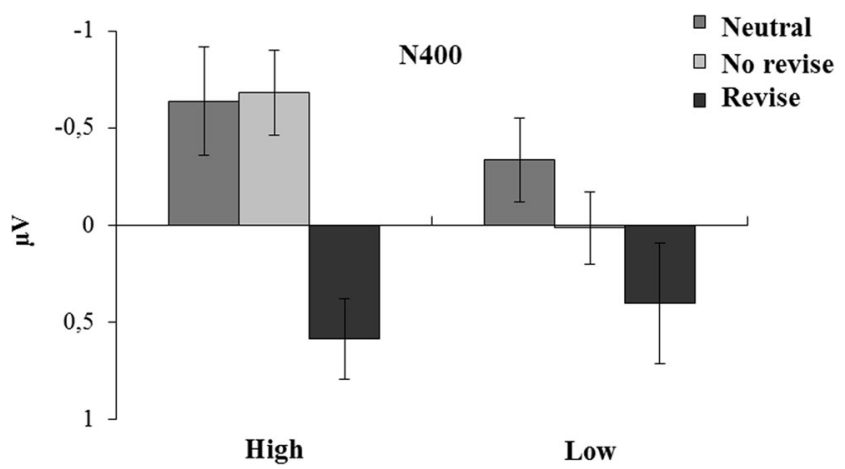

Fig. 4 Mean amplitude of the N400 component for the disambiguating word of the situation model revision task, divided by working memory group and condition

\section{Discussion}

The goal of this study was to investigate the dynamics of inferential revision in adults' reading comprehension, using both behavioral and electrophysiological measures. To do so, we created a bespoke reading comprehension paradigm: the situation model revision task. In this, the introduction (Sentences 13) provided a general context that facilitated at least two plausible inferences, one of which was more likely than the other. Sentence 4 was either neutral, did not require a revision (no revise) because it was inferentially consistent with the most likely concept, or did prompt a revision (revise) because the description prompted an inference that was consistent with only the less likely concept. Our behavioral results indicated that all participants took longer to read this sentence in the revise compared to the neutral and no revise conditions.

The final sentence ended with the disambiguating word, which was always inconsistent with the most likely concept but consistent with less likely concept supported in the revise condition. Here, our electrophysiological results differed by the specific ERP component. There were no working memory differences in the amplitude of the P3a: both memory groups presented larger positivity in the neutral and no revise conditions compared to the revise condition. In contrast, the pattern of findings for the P3b differed by working memory group: the high memory group showed significantly larger positivity in the neutral and no revise conditions compared to the revise condition, while the low memory group did not differ between conditions. Similarly, there were working memory differences in the N400 component: the high memory group demonstrated larger negativity in the neutral and no revise conditions than in the revise condition; however, the low memory group did not show a difference between the no revise and the revise condition, although a difference was apparent between the neutral and the revise condition.

\section{Evaluation at the inferential level}

In our texts, Sentence 4 of the revise condition always mismatched the interpretation supported by the introduction. The question was then whether readers were able to detect mismatches with their current situation model even though this information was processed at the inferential level. The reading time results demonstrated a large cost for both working memory groups, suggesting that all readers detected a mismatch between the new inferable information and the inference that was supported by the introduction of the text. In addition, the difference in reading times found between the neutral and revise conditions confirmed that the initial interpretation (e.g., 'guitar') was inferred by readers and incorporated into the situation model. Therefore, our behavioral results signal that when a highly constrained semantic context is provided, both high and low working memory readers are equally able to infer a knowledge-based elaborative inference and subsequently detect inferential information that is incompatible with that elaboration. This finding indicates that the evaluation process of monitoring may occur at the inferential level, which is congruent with other studies demonstrating that adults are able to evaluate their inferential comprehension (e.g., Poynor \& Morris, 2003). In addition, it is also consistent with the minimalist hypothesis (McKoon \& Ratcliff, 1980), which has claimed that elaborative inferences are automatically encoded during reading when 1) information is quickly and easily available in memory, or 2) they are necessary to provide coherence by text information or prior knowledge. Nevertheless, as we previously mentioned, our sentences were constructed so that the mismatch was easily detected. Thus, it is possible that working memory differences could arise if more subtle mismatches were introduced in these sentences.

A less clear matter is whether readers successfully revised their situation model after reading the revise condition in Sentence 4. From our point of view, two things could be happening here. One possibility is that readers activated and encoded the alternative interpretation (e.g., 'violin') and reduced activation of the initial interpretation. This would reflect revision of the memory representation. Alternatively, they may have activated and encoded the alternative interpretation without reducing activation of the initial interpretation. This would reflect a lack of revision of the memory representation. The reading times by themselves only speak to the evaluation process of comprehension monitoring, and do not clarify if the revision process took place when reading Sentence 4 . The electrophysiological data recorded in the disambiguating word address this critical issue.

\section{Evaluation and revision processes: $\mathrm{P} 3 \mathrm{a}$ and $\mathrm{P} 3 \mathrm{~b}$}

According to the context-updating theory (Polich, 2003, 2007), the P3a occurs when incoming information demands attentional control because it is evaluated as 'new' or 'different' with respect to the current memory representation; in contrast, the $\mathrm{P} 3 \mathrm{~b}$ appears when that incoming information forces subsequent attentional resources to favor context 
updating by memory operations. Although this theoretical framework has been developed using a traditional attentional task (oddball paradigm), our situation model revision task produced results that are consistent with this framework.

First, we found larger positivity associated with the P3a in the neutral and no revise conditions compared to the revise condition. This effect indicates that readers required greater attentional control on reading the disambiguating word (e.g., 'violin') when earlier information had not prompted a revision (e.g., 'beautiful curved body'-no revise; 'national concert hall'-neutral), but not when it had prompted one (e.g., 'matching bow'-revise). Thus, in general, readers were able to detect a difference or mismatch between the new (disambiguating) word and their current situation model. Interestingly, the lower positivity found in the revise condition also signaled that readers activated the alternative interpretation when reading Sentence 4. Second, we also found larger positivity associated with the $\mathrm{P} 3 \mathrm{~b}$ in the neutral and no revise conditions compared to the revise condition. However, the P3b effect was qualified by an interaction with group. Critically, the high memory group manifested smaller positivity related to the $\mathrm{P} 3 \mathrm{~b}$ for the revise condition relative to the other two conditions, while the low memory group did not show significant differences between conditions. These working memory differences found for the P3b suggest that the two groups had engaged in different processing when they read Sentence 4 in the revise condition.

On the one hand, the P3a findings indicate that both high and low working memory readers perceived the disambiguating word as 'new' when prior text information had not prompted a revision. That is, all readers detected the mismatch between that word and their current situation model. Of note, this is convergent with the reading time data: all readers detected the mismatch between Sentence 4 and the introduction in the revise condition. Thus, both the behavioral and P3a results suggest that adult readers are able to evaluate their comprehension during reading. On the other hand, the $\mathrm{P} 3 \mathrm{~b}$ findings indicated that high and low working memory readers differed in their way to revise the situation model. The smaller positivity for the revise condition relative to the other two conditions manifested by the high memory group signaled that this group did not require additional memory processes to update their situation model on reading the disambiguating word, because they had already revised their situation model on reading sentence 4 . Therefore, the high memory group had not only evaluated their comprehension detecting a mismatch (as indicated the longer reading times and the P3a) on reading Sentence 4, but also had revised their situation model, updating the final interpretation and significantly reducing activation of the previous interpretation. In contrast, the low memory group did not show significant differences between conditions for the P3b. This lack of differences indicated that the low memory group had not successfully revised their situation model on reading
Sentence 4 in the revise condition because they had difficulties drawing activation away from the initial interpretation.

This interpretation is congruent with studies demonstrating that poor comprehenders with poor working memory capacity have problems in inhibiting irrelevant information (Cain, 2006; Carretti et al., 2004; Pimperton \& Nation, 2010). It is also consistent with the Structure-Building framework (Gernsbacher, 1990, 1997), which argues that low working memory readers may experience problems with comprehension, because they fail to suppress no longer relevant information due to the generation of new substructures that reduce coherence of the situation model (e.g., Gernsbacher \& Faust, 1991). In relation to this, a more specific proposal in the field of revision suggests that the information that is no longer relevant or outdated may exert an influence disrupting comprehension (e.g., Kendeou et al., 2013; O’Brien et al., 2010; Rapp \& Kendeou, 2007, 2009). Taking all this evidence into account, our P3b results indicate that, in contrast to high working memory readers, low working memory readers have problems revising their situation model because they fail to inhibit the initial wrong interpretation. In addition, the presence of inferred information could make the revision of the situation model more difficult for low working memory readers, who may construct a more 'imprecise' or 'inaccurate' mental representation of the story. This is consistent with the literature of inference alteration, which suggests that memory processes are involved when an inference that has been previously activated must be replaced by a new one (e.g., Radvansky \& Copeland, 2004). The process of integrating text information into a coherent situation model sheds light on this issue.

\section{Integration process: $\mathbf{N 4 0 0}$}

Similar to the P3b, the analysis of the N400 demonstrated that working memory capacity underpinned the ability to integrate information into the situation model. The high memory group showed larger negativity in the neutral and no revise conditions compared to the revise condition. This result indicated that they experienced difficulties with integrating the disambiguating word into their situation model when earlier text information had not required a revision; in contrast, they did not experience difficulties when a revision had been prompted by the text. Thus, high working memory readers were able to integrate the alternative interpretation into their situation model on reading Sentence 4 in the revise condition (supported by the reading time results). A different pattern was evidence for the low memory group, broadly similar to that found for the $\mathrm{P} 3 \mathrm{~b}$ : they showed no significant difference between the no revise and the revise condition, although larger negativity was found in the neutral condition compared to the revise condition.

The lack of difference between the no revise and the revise condition for the low working memory group strongly suggests that they had not successfully integrated the alternative 
interpretation into their memory representation on reading Sentence 4 in the revise condition. Both critical concepts (e.g., 'guitar/violin') shared similar semantic properties, which could potentially interfere and disrupt the construction of an accurate situation model. Moreover, the difference found between the neutral and the revise condition suggests that the low working memory group was able to integrate the alternative concept, reading the disambiguating word only when the neutral condition was presented in Sentence 4, because the nature of the neutral information (not related with the critical concept) did not cause semantic interference. These results are congruent with those studies showing the pervasive effect of semantic interference in relation to updating the contents of working memory (e.g., Szmalec, Verbruggen, Vandierendonck, \& Kemps, 2011). Therefore, low working memory readers seem to be able to accurately integrate new information into the situation model under some circumstances, but they experience difficulties if that information semantically interferes with other information that is already encoded.

A compatible hypothesis that cannot be ruled out in this study is the possibility that the activation of the N400, and therefore the level of integration into the situation model, could be related to the degree of awareness with which readers detected the unexpected information. Unfortunately, we did not systematically ask participants if they had noticed anything 'odd' in the texts. However, there was a tendency for some participants to report this. Future research should include checks for awareness of inconsistencies in the debriefing and analyses of these to determine if differences in awareness exist between memory groups.

\section{A comprehensive view}

Our findings can be understood within Kendeou and O'Brien's (2014) KReC framework. This proposes five key principles that are required for knowledge revision within a situation model during reading: encoding, passive activation, co-activation, integration, and competing activation. In relation to our paradigm, it means that once the previous interpretation (e.g., 'guitar') is encoded and passively activated from long-term memory, the presentation of information supporting the revised interpretation (e.g., 'matching bow') will cause the co-activation of both interpretations (e.g., 'guitar/violin'). Furthermore, the revise information of Sentence 4 will lead to the integration of the alternative interpretation (e.g., 'violin') within the situation model, drawing activation away from the previous but now-incorrect interpretation and reducing the interference between the two (competing activation).

Applying the KReC logic to our results, the evaluation of mismatched information (prompted by Sentence 4), requires both the activation and integration of the two interpretations, whereas the revision of the situation model (prompted by the disambiguating word) involves the better integration and increase in activation of the new concept. Therefore, on the one hand, a failure to co-activate both interpretations and to integrate the new information will result in problems in evaluation, because no incompatibility will be detected. On the other hand, a failure to integrate, together with a deficient competing activation of the final concept, will cause difficulties in revision, because activation will remain in the nowincorrect interpretation, hampering stronger activation of the new concept. Our data suggest that low working memory readers have problems revising their situation model, because the activation of the previous interpretation continues to compete (by semantic interference) with the new concept. That is, these readers have problems strengthening the activation of the final concept because they fail to inhibit the wrong interpretation. We believe that this is a promising framework for the future study of the inferential revision process.

Finally, to better understand our results it is important to consider the processes that were evaluated in the two working memory tasks and how they relate to the reading comprehension processes studied here. The reading span task was used as an index of the ability to actively maintain information, making it readily retrievable (Daneman \& Carpenter, 1980), while the memory updating task was selected to measure the suppression of no longer relevant information (e.g., Carretti et al., 2010). Our situation model revision task tapped both of these aspects of working memory: it required the activation and maintenance of the previous interpretation as well as the inhibition of that interpretation when a more plausible inference was apparent. This viewpoint is not incompatible with Engle's (2002) perspective that working memory reflects the ability to allocate attentional resources when the task involves interference control to maintain or suppress information. We believe that the ability to actively maintain and suppress no-longer-relevant information, combined with the need to control interference, are both crucial in explaining how individual differences in working memory are related to the inferential revision process.

\section{Conclusions}

To our knowledge, this is the first study to report ERP data associated with the inferential revision of readers' situation models. We have proposed that the context-updating theory is a promising framework to dissociate the comprehension monitoring processes of evaluation and revision. Through this, we have identified where in the reading process readers with poor working memory have difficulties revising their situation model. Our ERP data provide evidence that strongly suggest that low working memory readers are able to evaluate their comprehension and detect coherence breaks in the text (evidenced by the P3a), but that they have difficulties revising their memory representation because they fail to inhibit an 
initial wrong interpretation (P3b) and integrate new information to ensure an accurate situation model (N400).

Acknowledgments This study has been supported by a grant of the Spanish Ministry of Education and Science (FPU) to A. P., by grants of MINECO-PSI2012-33625 and JA-2012-CTS 2369 (Proyecto Excelencia) to T. B., and by the Department of Psychology of Lancaster University (UK). In addition, we would like to thank Thomas Lorsbach for providing his materials, Kate Nation and Holly Joseph for their contribution in the construction of some of the additional materials, and Sasha Smith for help with our norming studies.

\section{Appendix A. Full set of materials of the situation model revision task.}

\section{The walk butterfly/bird}

- It was a beautiful summer's day and the flowers in the park were in bloom.

- Mrs. Flynn was walking past the flowerbed with her little boy Mike.

- She spotted something flying up into the sky.

- Mike was looking at the ground trying to pick up a yellow flower. (Neutral)

- It had decorated wings and was gracefully rising from a delicate flower. (No revise)

- It had colored feathers and was loudly singing a beautiful melody. (Revise)

- Mrs. Flynn pointed to the sky to show Mike the bird.

It was winter time. [No]

\section{Jack and Andy snowman/snowballs}

- It had been snowing and all the children were playing in the park.

- Jack and Andy were best friends and worked well as a team.

- They had spent 30 minutes rolling up snow and now they were nearly ready.

- Andy's hands were frozen because he had forgotten his gloves. (Neutral)

- Andy had brought an old woollen scarf and hat to put on. (No revise)

- Andy thought that they now had sufficient missiles to win the fight. (Revise)

- In the end, they were really pleased with their snowballs.

The children were in the park. [Yes]

\section{The cleaner bathroom/kitchen}

- The cleaner had so much work to do, she had not yet had time to stop for a rest.

- She wiped down the tiles, cleaned the soap dish, and then rinsed out her cloths.

- Now, as she stood there, she wanted a break.

- When she had finished the housework, she would take the rubbish outside. (Neutral)

- The cleaner thought about cleaning the toilet and that grimy shower. (No revise)

- The cleaner opened the refrigerator and took out some cheese and salad. (Revise)

- She left her cleaning things on the floor in the kitchen.

The cleaner did not have much work to do. [No]

\section{The puppy rain/bath}

- Today it was raining again.

- Inside the house it was nice and warm.

- A small brown and white puppy stood dripping by the door.

- Meanwhile, the television news could be heard from the living room. (Neutral)

- The puppy scratched and whimpered on the door waiting for his owner. (No revise)

- The bathroom door opened and his owner came in with a thick towel. (Revise)

- The owner had fetched a towel to dry the puppy after the bath.

It was warm inside the house. [Yes]

\section{The office headteacher/dentist}

- The school secretary came into the classroom.

- Gillian was told to report to the office, because she had an appointment with Mr. Brown.

- Gillian followed slowly, wishing she could be back in class.

- The long main corridor of the school was empty and quiet. (Neutral)

- Mr. Brown was thinking about how to correct her problems. (No revise)

- Her mother was waiting to take her to have her teeth checked. (Revise)

- Gillian dreaded her appointments with the dentist.

Gillian was told to report to the playground. [No] 
6. The needle operating/dressmaking

- It had been a long day at the hospital.

- Ann, the surgeon, felt tired, but wanted to get on.

- After adjusting the lamp, she threaded the needle and began.

- Ann's reading glasses were pushed down right onto the tip of her nose. (Neutral)

- She thought one last time about the length of the delicate cut. (No revise)

- She thought about the color of the buttons for the jacket she was making. (Revise)

- Ann was surprised by how good she was at dressmaking.

Ann adjusted the lamp. [Yes]

\section{The new addition baby/kitten}

- Mr. and Mrs. Jones were proud of the new addition to their family.

- Lots of family and friends had been round to have a look.

- Mrs. Jones knew that she would have to be patient with the regular feedings.

- Winter was coming, so today they decided to light the fire. (Neutral)

- The tiny new arrival always seemed to be hungry and cried often. (No revise)

- The tiny new pet always seemed to be hungry and meowed often. (Revise)

- Mr. Jones sat on the chair, holding the small kitten.

Family and friends had been round to visit. [Yes]

\section{The firefighter building/plane}

- The firefighter looked out of the window.

- He felt quite anxious, because everyone was watching.

- Soon he would have to jump and he had never done this before.

- He looked at his shoes and thought about how good they were for jumping. (Neutral)

- He took a deep breath to calm himself and signalled that he was ready. (No revise)

- He checked his parachute and signalled to the pilot that he was ready. (Revise)

- The others watched him jump from the plane.

The firefighter looked down from the balcony. [Yes]
9. The big game stadium/home

- Today was the league cup final.

- Tommy's team was in the final and it had been difficult to get tickets.

- The sound of the whistle signalled the beginning of the first half.

- The newspapers had been predicting their victory for two weeks. (Neutral)

- Tommy and his father both leaned forward excitedly. (No revise)

- Tommy and his father leaned forwards on the sofa, excitedly. (Revise)

- Tommy and his father were watching the match together at home.

Tommy's team was in the final. [Yes]

10. The park slide/swing

- Jenny loved to play at the park near her home.

- Today she had decided to spend some time on the playground equipment.

- What fun it was to climb up to the top and then come back down to the ground.

- She liked having Mum there, sitting on the bench nearby, waiting for her. (Neutral)

- She liked having Mum there to greet her each time she came down. (No revise)

- She was going back and forth through the air being pushed by her mom. (Revise)

- Then Jenny's mother said that it was time to get down from the swing.

Jenny loved to play at park. [Yes]

11. The house buying/burglary

- The man saw the "For Sale" sign outside the large house in a wealthy neighbourhood.

- He had been looking for a place like this for quite a while.

- He made an appointment with the estate agent to view the house.

- The man arrived early and waited for the estate agent in front of the house. (Neutral)

- The man told the estate agent about his desire to move into the area and asked for the price. (No revise)

- The man was a criminal thinking about all the valuable things in the house. (Revise) 
- Once in the house, the man started to plan his burglary.

The man saw a "For Sale" sign. [Yes]

\section{The lion gun/camera}

- The famous hunter was on another safari in the jungles of Africa.

- Even though he had hunted for years, this time it felt very different.

- Today, the hunter found a lion's trail and followed it until he got close to the lion.

- He adjusted his cap to see properly and looked straight at the animal. (Neutral)

- He focused on the lion, steadied his hand, and took the shot. (No revise)

- He focused on the lion, looking for a nice photo, and took the shot. (Revise)

- The lion startled when he heard the sound of the camera.

The safari was in the jungles of Africa. [Yes]

\section{The tracks deer/train}

- Annie and her father lived out in the Midwest of America, near a crossing.

- There had been a snowfall over night.

- At the window, her father asked Annie if she could see the tracks.

- $\quad$ The window was misted up, so Annie wiped it with her hand. (Neutral)

- $\quad$ There was an animal with antlers walking slowly in the snow. (No revise)

- There was a loud whistle and smoke rose into the sky. (Revise)

- In the snow, Annie could see the tracks of the train.

Annie and her father lived in the Middle East. [No]

\section{The stable lad horse/bike}

- Harry worked as a stable lad and this was his first race.

- He was a good rider, but this was going to be a difficult race.

- There were lots of excellent riders from all over the county.

- Before the start, he looked up at the sky and crossed himself. (Neutral)
- He was wearing his favorite jeans and his hat for good luck. (No revise)

- He checked the height of the handlebar, pedals and both wheels. (Revise)

- The race began and his family cheered as he took the lead on his bike.

There were lots of excellent riders. [Yes]

\section{The vampire garlic/onion}

- Christine and her friends went to see a horror movie at the cinema.

- It was about some vampires and the villagers who tried to stop them.

- The climax of the movie was when a brave young girl tried to kill the vampire.

- $\quad$ The audience was gripped by the unfolding horror. (Neutral)

- $\quad$ The vampire would die if he ate the white vegetable. (No revise)

- The vampire would die if he ate the round vegetable that it makes cry. (Revise)

- In the end, Christine was glad to see the vampire die after eating the onion.

The reviews of the film were bad. [No]

\section{The destination hospital/library}

- Erin was not feeling well so she took a bus into the city.

- She was hoping that she would soon find out what was wrong.

- The bus stopped right outside her destination.

- $\quad$ The people waiting at the bus stop started to board the bus. (Neutral)

- She thought about her last trip here, when she had a broken leg. (No revise)

- She thought about the last time that she came here to borrow a book. (Revise)

- She walked through the door and entered the library.

Erin took a taxi into the city. [No]

\section{The mystery character/murderer}

- The man lived alone in the huge mansion.

- This evening, he was sitting on the sofa reading his detective novel.

- The curtains were closed and everything was silent. 
- The cuckoo clock sounded at 8 p.m., ending with a soft bell sound. (Neutral)

- Turning the page, he knew that someone had entered the house with a knife. (No revise)

- He heard someone enter the room and saw them standing there with a knife. (Revise)

- The man thought that the knife would be used by the murderer.

The curtains were open. [No]

18. Cooking stove/campfire

- Frank and his father were discussing what to have for dinner.

- The decision would have been easier if mum had been there.

- Finally, they decided to cook pasta and meatballs.

- Frank wanted to make two meatballs for him and three for his father. (Neutral)

- Frank filled the pan with water and added a pinch of salt. (No revise)

- Frank arranged some twigs and his father got out the matches. (Revise)

- Frank's father told his son to keep an eye on the campfire.

Frank and his father decided to cook steak. NO

19. The fish shark/squid

- It was a hot summer's afternoon.

- Peter and his friends were at the beach.

- Peter ignored the warning flag and went for a swim.

- Peter made out a small shape of a sailboat on the sea near the horizon. (Neutral)

- Suddenly, Peter recognized the shape that was swimming towards him and felt the fear in his bones. (No revise)

- Suddenly, Peter saw the tentacles of the animal moving towards him and felt curious. (Revise)

- It was the first time that Peter had seen a squid.

There was a warning flag. [Yes]

\section{The workman hammer/tyre}

- The workman had a busy day ahead.

- He had his long ladder, his power saw, and a stack of timber ready for him.

- Everything was going well, until he struck that nail.
- He had forgotten the phone, so he could not call anyone at that moment. (Neutral)

- He was always very careful and wore gloves to protect his hands. (No revise)

- He was driving along, when he spotted the big nail in the road ahead. (Revise)

- The workman knew that the nail had damaged the tyre.

The workman had a long ladder and a power saw. [Yes]

21. The breakfast $\mathrm{bacon} / \mathrm{cereal}$

- After his shower, Billy went downstairs to the kitchen.

- A welcoming smell greeted him.

- His girlfriend, Susie, was standing by the cooker preparing breakfast.

- $\quad$ Susie said good morning and smiled across at him. (Neutral)

- Susie had already laid the table and made the coffee. (No revise)

- On the table, Susie had put out bowls and spoons. (Revise)

- Billy's stomach rumbled as he waited for his cereal.

The kitchen was upstairs. [No]

\section{Baking cookies/decorations}

- Jim and Jane were in the kitchen mixing the flour and butter with enthusiasm.

- Once the dough was ready, they rolled it flat.

- They cut the dough into different shapes and baked them in the oven.

- $\quad$ Their father snorted when he saw the mess they had made in the kitchen. (Neutral)

- Then the children waited eagerly while the small pieces cooled on a plate. (No revise)

- Then the children painted the small pieces before hanging them on the Christmas tree. (Revise)

- The children's mother was proud with the shapes of the decorations.

Jim and Jane rolled the dough flat. [Yes]

\section{The memory armchair/hammock}

- Bryan had returned to see his childhood home, back in northern Texas.

- It had a veranda, which looked onto a large garden. 
- He remembered how his mother would always go there to read, after lunch.

- The window panes were broken and the house was now empty inside. (Neutral)

- He could remember her humming gently, as she read in the shade. (No revise)

- He remembered her lying there, swinging between the two stout trees in the shade. (Revise)

- Bryan felt nostalgic and wished he could be in his mother's hammock.

The house was in northern Moscow. [No]

\section{The lunch girlfriend/neighbour}

- This Sunday, Joseph invited his girlfriend round to his new flat for lunch.

- He checked the roast in the oven, set out the table, and waited for her to arrive.

- At half past twelve the doorbell rang and Joseph went to the door.

- At the same time, the oven timer indicated that the roast was ready. (Neutral)

- Claire was standing there with a cake for dessert. (No revise)

- Claire, from downstairs, had brought round his post. (Revise)

- Joseph opened the door and said thanks to his neighbour.

The doorbell rang at two o'clock. [No]

\section{The wedding straight/gay}

- It was the day of Robert's wedding.

- He dressed himself carefully, imagining his partner in the same situation.

- His best man drove him to the registry office in good time.

- Many of his friends and relatives were there waiting for his arrival. (Neutral)

- Looking around, Robert spotted the blonde hair of his future spouse. (No revise)

- Looking around, Robert spotted the blonde beard of his future husband. (Revise)

- Today, Robert felt especially proud to be gay.

Robert dressed himself quickly. [No]
26. The thirsty water/lemonade

- The runner had now been running for over an hour.

- During that time, she had not had anything to drink.

- She was incredibly thirsty and took a drink from the table as she went past.

- After drinking she tossed the bottle into a bin and continued running. (Neutral)

- She drank the clear liquid in two gulps and felt much better. (No revise)

- She drank the sweet, clear, sparkling liquid and felt much better. (Revise)

- The runner would be able to finish the race now she had drunk some lemonade.

The runner took the drink from the bar. [No]

\section{The baby pregnancy/adoption}

- The couple was very excited.

- Soon they would be parents.

- They both remembered the time when they knew they would have a baby daughter.

- $\quad$ They had painted the room pink and bought lots of toys. (Neutral)

- Nine months had felt long enough and now they wanted to see their baby. (No revise)

- It had taken nine months to get the paperwork completed for the Chinese baby. (Revise)

- In the end, they realized that nine months was not that long to wait for an adoption.

The baby was a girl. [Yes]

\section{The farm cat/dog}

- On the farm, the horses were in the stable because it was raining.

- Down in the straw, a mouse was looking for something to eat.

- A bigger animal, hidden in the corner, was watching.

- $\quad$ The mouse found a piece of fruit and began to eat. (Neutral)

- It jumped out and scared the mouse. (No revise)

- It barked loudly and scared the mouse. (Revise) 
- Farmer Campbell walked into the stable and saw the mouse in the mouth of his dog.

It was a sunny day. [No]

\section{The darkness candle/lamp (electrical)}

- It was a warm summer's night and Bruce was in his room playing his guitar.

- The room was softly lit with a warm smell of incense.

- The window was open and there was a gentle wind outside.

- Bruce was playing his favorite song when it went dark. (Neutral)

- Suddenly, the light flickered and blew out leaving Bruce in darkness. (No revise)

- Suddenly, the bulb flickered and Bruce was left in darkness. (Revise)

- Bruce put down his guitar and walked over to the lamp.

The window was closed. [No]

\section{The couple wife/lover}

- The couple who walked into the hotel lobby could not take their eyes off each other.

- I wondered if they were newlyweds.

- The man put his arm around the woman and they walked to the elevator.

- When the elevator arrived, the couple entered it and I did the same. (Neutral)

- I saw the man bend down and kiss the woman just behind her ear. (No revise)

- $\quad$ The man slipped off his wedding ring and put it in his pocket. (Revise)

- Once in the elevator I realized that the woman was his lover.

The couple could not take their eyes off each other. [Yes]

\section{The gully falling (suicide)/paragliding}

- Some people thought that David was an unlucky man.

- He had lost his job and now his wife had left him.

- Today he drove up to the clifftops near his home.
- After parking, he got out of the car and stood thinking for a while. (Neutral)

- After a while standing there, he ran to the edge and jumped. (No revise)

- He checked his parachute and jumped off the edge. (Revise)

- Once in the air, David fell quickly while paragliding.

David had driven up to the clifftops. [Yes]

\section{The artist painting/cake}

- The artist admired his creation as he brushed his dirty hands on his apron.

- It was almost perfect.

- Now he just had to add the finishing touches.

- $\quad$ The doorbell rang just as the artist had finished. (Neutral)

- He mixed some blue to make his distinctive mark. (No revise)

- He mixed some more icing to add to the sides. (Revise)

- His wife was surprised when he gave her the cake.

The artist brushed his hands on his apron. [Yes]

33. The long day swim/bath

- Jodi stood on the hotel balcony.

- There were only a few people in the pool, below.

- Jodi quickly changed out of her dress and was soon ready to get into the water.

- It was her second day at the hotel, and she still had three more days left. (Neutral)

- Before getting in, she dipped in her foot to check the temperature. (No revise)

- When she had run the water, she checked the temperature with her hand. (Revise)

- All day long, Jodi had been looking forward to that bath.

There were a lot of people in the pool. [No]

\section{The logs $a x / s a w$}

- Dave looked at the fallen branch.

- It would make excellent logs for the fire.

- He went to the shed to fetch his favorite tool. 
- The shed was cluttered but he quickly found the tool. (Neutral)

- The handle was smooth from years of use. (No revise)

- The serrated blade looked a little rusty. (Revise)

- Dave put on his gloves and picked up his saw.

Dave had gone to the garage. [No]

\section{The juice orange/apples}

- My daughters drink lots of fruit juice.

- This year, I bought a juicer so I can make it fresh each day.

- Pam, my youngest, is fussy and prefers one type of juice.

- In fact, she will only drink her juice through a straw. (Neutral)

- Her favorite fruit is round and contains plenty of vitamin $C$. (No revise)

- Her favorite fruit has red peel and comes from our own orchard. (Revise)

- Now, every morning to make the juice I have to peel three apples.

Pam is the oldest sister. [No]

\section{The funeral burial/cremation}

- Today was the funeral of the much loved aunt.

- The priest had said the prayer.

- Now it was time for the family to say their final goodbye.

- The daughter expressed sadly her love to her. (Neutral)

- The daughter placed a single rose on the coffin. (No revise)

- The family planned to scatter the ashes in the rose garden. (Revise)

- It was the first time that the children had been to a cremation.

The prayer was said by a relative. [No]

\section{The sleeplessness fever/nightmare}

- The little girl had not been well for several days.

- However, tonight she was back in her own bedroom, sleeping alone.

- In the middle of the night, she woke up in a sweat and felt delirious.
- Her mother woke up and came into her room. (Neutral)

- Her mother came in and told her not to worry. (No revise)

- Her mother came in and said it was just a bad dream. (Revise)

- The mother hoped that soon there would be an end to the nightmares.

The little girl was sleeping alone. [Yes]

38. The musician guitar/violin

- Dan was a gypsy who had played flamenco since childhood.

- Now he is a popular musician who plays all over the world.

- Today, he is giving a recital of his favorite works.

- The concert takes place at the prestigious national concert hall. (Neutral)

- His instrument is made of maple wood, with a beautiful curved body. (No revise)

- His instrument is made of maple wood with a matching bow. (Revise)

- The public was delighted to hear Dan playing the violin.

In the recital, Dan played his favorite works. [Yes]

\section{The event fight/play}

- The tension between the two men was high.

- One of them took advantage and smacked the other straight on the jaw.

- The people watching could not believe what they were seeing.

- $\quad$ One of the men was older with slightly graying hair. (Neutral)

- $\quad$ The men became more and more aggressive. (No revise)

- The actors were very convincing in their roles. (Revise)

- That moment was the most violent of the play.

One man smacked the other on the leg. [No]

40. The cinema popcorn/ice-cream

- Grace was very excited when she got to the cinema.

- It was the premiere of the film based on the book she had just read. 
- She bought a soft drink and a large tub of her favorite snack, which she only ever bought at the cinema.

- As soon as she sat down, Grace relaxed and focused on the screen. (Neutral)

- As soon as she sat down, Grace opened the tub and began to eat. (No revise)

- As soon as she sat down, Grace undid the wrapper before it melted. (Revise)

- In five minutes, she had finished eating her icecream.

The film was based on a book. [Yes]

\section{The removal mirror/photograph}

- Mr. and Mrs. Harrison were in their new apartment.

- They were unpacking their belongings and deciding where to put everything.

- Mrs. Harrison was looking for something to hang on the bathroom wall.

- She found some wire and a hook and hung it on the wall. (Neutral)

- She saw her reflection in the glass as she picked up the frame. (No revise)

- She looked at the wedding scene as she picked up the frame. (Revise)

- Mr. Harrison said it was a beautiful photograph.

Mr. and Mrs. Harrison had a new apartment. [Yes]

\section{The excursion zoo/aquarium}

- Emma is a five years old girl who loves animals.

- Today she is especially happy.

- Her parents are taking her to her favorite place.

- It took almost an hour to get there, but at last they arrived. (Neutral)

- There she can see creatures from all over the world. (No revise)

- There she can see many fish of various colors and shapes. (Revise)

- She looked at the huge sign over the entrance, which read aquarium.

Emma's grandparents were taking her out. [No]

\section{The field $\mathrm{bull} / \mathrm{cow}$}

- Ed was lying on his back in the field on a warm summer's day.
- He heard a noise and looked up and saw the huge black animal.

- Ed felt terrified looking into its big eyes whilst it towered over him.

- Ed closed his eyes and stayed still, hoping the animal to go away. (Neutral)

- The big animal had big horns and ring through its nose. (No revise)

- The big animal with udders moved its leg, and mooed loudly. (Revise)

- The farmer shouted and scared the cow.

The animal was brown. [No]

44. The hike head/bottle

- Sam was proud to be a member of his Boy Scout troop.

- Today, the troop was on a hike up a mountain.

- It was a sunny day and as they got near the summit the wind picked up.

- Sam grabbed his bag tightly and hurried on with determination. (Neutral)

- Sam noticed the wind and made sure that he pulled his cap on tight. (No revise)

- Sam had a drink and made sure that he fastened the cap tight. (Revise)

- The scoutmaster understood why Sam secured the cap on his bottle.

The troop was going to the beach. [No]

45. The immigrants headscarflhairband

- The Muslim family was having problems integrating into the new society.

- For example, little Eylem's first day of school was very stressful for her.

- The other children were mean and pointed at her at her head.

- During break time, Eylem preferred sit alone away from the other children. (Neutral)

- Eylem had got dressed in her usual clothes for school that day. (No revise)

- Eylem had tied back her hair to keep it off her face. (Revise)

- The teacher punished the children who mocked at Eylem's hairband.

It was the first day of school for Eylem. [Yes] 
46. The bus inspector/passenger

- It was a cold January morning.

- The bus to the University arrived; I got on and found a seat.

- A serious man wearing a peaked cap and jacket got on as well.

- The bus doors closed and the driver pulled back out into the road. (Neutral)

- The man checked the date and the wording on each ticket very carefully. (No revise)

- The old man checked his own ticket closely, trying to read the date. (Revise)

- I noticed the thick glasses worn by this passenger.

It was a July morning. [No]

\section{The rain umbrella/anorak}

- Today, it was raining heavily.

- Liza had an important meeting and did not want her hair to get ruined.

- Before leaving the house, she grabbed something to keep herself dry.

- She also picked up her computer bag, which she had packed the night before. (Neutral)

- It was still there in the porch, where she had left it to dry last night. (No revise)

- It was hanging by its hood in the porch, where she had left it to dry. (Revise)

- On her walk to work, Liza was glad that she had an anorak.

Liza did not want her shoes to get ruined. [No]

\section{The horoscope newspaper/computer}

- On Saturday mornings, Sara always reads her weekly horoscope.

- She looks forward to this all week.

- This Saturday, she made herself some coffee and sat in her favorite chair.

- She had all morning to read quietly. (Neutral)

- She went straight to the right page. (No revise)

- She clicked straight on the right link. (Revise)

- She carefully read her horoscope on the computer.

Sara reads the weekly horoscope on Sundays. [No]
49. The desert camel/snake

- Tuaregs are Berber nomadic people, inhabitants of Sahara's desert.

- The Tuareg Isham had been travelling with his animal through the dunes on a long journey.

- He stopped at an oasis so that they could both drink.

- $\quad$ They were both thirsty and Isham needed to rest for a while. (Neutral)

- The brown animal next to him was waving its tail slowly. (No revise)

- The animal was slithering next to him, its forked tongue darting. (Revise)

- After hours, Isham found an oasis where he could give some water to his snake.

Isham had been moving through some dunes. [Yes]

\section{The energy-giving drink coffee/coke}

- By mid-morning, Eve always felt a little tired.

- She would go down to the drinks machine to get her daily pick-me-up.

- She put the coins in the slot and entered the code.

- In a few minutes she was back at her desk with the drink. (Neutral)

- The drink always gave her the mid-morning boost she needed. (No revise)

- The fizzy cold drink tasted sweet and gave her a boost. (Revise)

- Eve always felt perkier after her coke.

Eve had to enter a code for her drink. [Yes]

\section{The jungle lion/elephant}

- Many different animals were gathering around the waterhole.

- This was a popular spot at this time of day.

- The antelope looked nervous when the newcomer arrived.

- It was very hot and the water cooled them down nicely. (Neutral)

- The animal walked slowly waving his tail. (No revise)

- The animal walked slowly waving his trunk. (Revise) 
- The rest of animals moved to make space for the elephant.

Many animals were around the waterhole. [Yes]

\section{The skin chickenpox/acne}

- Alex was a rather sickly teenager.

- Today he did not feel well and told his mum that he did not want to go to school.

- He decided to stay in bed.

- His mother told him that he could stay at home. (Neutral)

- His mother noticed some small red spots on his face. (No revise)

- His mother noticed some pimples on his chin. (Revise)

- His mother went to the pharmacy and bought something for his acne.

Alex wanted to go to school. [No]

\section{Mr. and Mrs. Potter people/monkeys}

- Mr. and Mrs. Potter had lived together for a few years now.

- They used to exercise together, every morning.

- Mr. Potter was sick so he could not exercise at the moment.

- In the end, Mrs. Potter did not exercise that morning either. (Neutral)

- Mrs. Potter liked to stay with him for company. (No revise)

- Mrs. Potter stayed with him in the cage, grooming his fur. (Revise)

- Some families often came to visit these lovely monkeys.

Mr. and Mrs. Potter used to exercise together. [Yes]

\section{The morning bell/cockerel}

- Mr. Martin lives several miles out of town.

- Every morning, he wakes up early: it is a long drive to the office.

- It was six, when the noise woke him up this morning.

- After stretching he jumped out of the bed. (Neutral)

- The loud melody was repeated several times. (No revise)
- The loud crowing was repeated several times. (Revise)

- Mr. Martin thought it was great to be woken up by the cockerel.

It was six when the noise woke Martin up. [Yes]

55. The time watch/hourglass

- Four friends were playing a board game.

- Now it was Bob's turn and he had one minute to draw the word on the card.

- Debbie checked the time and then told Bob to start.

- Debbie kept laughing as she looked at Bob's drawing. (Neutral)

- Debbie watched the minute pass, second by second. (No revise)

- Debbie watched the sand trickle through, second by second. (Revise)

- Bob was not sure he would finish his drawing in time as he glanced at the hourglass.

Bob had to draw a picture of the word on the card. [Yes]

56. The dessert strawberry/blackberries

- After lunch, Mrs. Wells liked to have fruit for dessert.

- She grew her favorite fruit in her garden.

- Today, she decided to be decadent and have a bowlful with cream.

- She went back in the kitchen, got out a bowl and prepared her dessert. (Neutral)

- She removed the leaves carefully, so as not to damage the berries. (No revise)

- She removed the leaves carefully, so as not to get purple stains on her fingers. (Revise)

- Mrs. Wells got a spoon and started to eat the blackberries.

Mrs. Wells used to eat fruit for breakfast. [No]

\section{The fruit banana/lemon}

- Jessica was the most popular monkey in the zoo.

- She got lots of attention from the zookeeper, especially treats.

- That afternoon Jessica received a piece of fruit as treat. 
- Jessica realized that she was in the spotlight. (Neutral)

- Jessica savoured the taste of the yellow fruit. (No revise)

- Jessica sucked on the sour yellow fruit. (Revise)

- It was the first time that Jessica had tasted a lemon.

The zookeeper neglected Jessica’s diet. [No]

\section{The car repair/petrol}

- Oliver was driving up to Scotland when his car made an odd sound and then stopped.

- He called the breakdown service, which sent a breakdown van to assist.

- The van brought the car and its driver to the nearest garage.

- In less than an hour he was ready to continue his journey to Scotland. (Neutral)

- At the garage, a man quickly solved the problem with the car. (No revise)

- At the garage, they filled up the tank so the car was ready to go again. (Revise)

- Oliver was pleased and paid for the petrol.

The car and its driver were brought to the garage by a tractor. [No]

\section{The sky kite/balloon}

- Little Ben loved being pushed by his father in his pram.

- He would lie back and watch the birds in the sky above.

- Today it was windy and he saw something different in the sky.

- Ben sat up in his pram and stared up at the sky, smiling. (Neutral)

- It was shaped like a bird, but a boy carefully guided it with some strings. (No revise)

- It was red and round, and a boy was holding onto its string tightly. (Revise)

- Ben's father pointed out to show him the balloon.

Little Ben liked to lie back in his pram. [Yes]

\section{Shopping greengrocer/butcher}

- Mr. Smith ran his own shop on the high street, which sold organic produce.
- Although he ran a box scheme, many people still came in to the shop.

- The first customer today was the mayor's wife.

- $\quad$ She trusted Mr. Smith so she let him to advice her. (Neutral)

- She checked her list to see what items she needed. (No revise)

- She checked her list and bought a chicken and some sausages. (Revise)

- The woman paid the bill and thanked the butcher.

The first customer was a man. [No]

\section{The elevator $u p /$ down}

- I was visiting a dear old family friend who lives in an exclusive apartment block in Manhattan.

- I did not have to wait long for the elevator to arrive.

- When the door opened, I entered and pressed the floor number.

- In under a minute until the elevator doors opened and I could come out. (Neutral)

- $\quad$ The elevator doors opened smoothly and I saw Mr. Clark standing there. (No revise)

- The elevator doors opened and I saw the doorman waiting at the entrance. (Revise)

- In the elevator, I checked my phone for messages as it was going down.

My family friend lives in an exclusive apartment block. [Yes]

\section{The mount horse/donkey}

- The rider got out the saddle and reins and secured them.

- Everything was ready for his ride through the mountain vineyards.

- He got up on the saddle and started to ride.

- $\quad$ The first stop was after four kilometers, at the top of the mountain. (Neutral)

- The animal had a beautiful coat and a long tail. (No revise)

- The animal had long pricked up ears, and often brayed loudly. (Revise)

- The rider had an excellent view of the mountains on top of his donkey.

The rider secured the reins. [Yes] 


\section{Mexican beer bottle/can}

- It was Bob's birthday party and he was having a barbecue.

- He had bought lots of Mexican beer, which he was keeping cold in the fridge.

- Dave, his mate, handed him a fresh beer.

- Bob gave Dave a knowing wink, showing his appreciation. (Neutral)

- Bob found it hard to open because his hands were greasy from cooking. (No revise)

- Bob opened the beer and threw the ring-pull in the bin. (Revise)

- Finally, Bob opened the beer and drank from the can.

The beer was keeping cold in the garden. [No]

\section{The agreement flat/car}

- The landlord discussed terms and conditions with the new tenant.

- He often rented to new people and liked to show them around himself.

- The new tenant was anxious to come to an agreement.

- $\quad$ The landlord then fixed the conditions and the total price to pay. (Neutral)

- The landlord held the door open for the tenant to look around one last time. (No revise)

- The landlord showed him a small backroom where he could store spare tyres and oil. (Revise)

- The tenant accepted the terms and signed the contract to rent the car.

The tenant was anxious to come to an agreement. [Yes]

\section{The insect bee/dragonfly}

- Daphne was in the park having a picnic with friends.

- For the picnic, Daphne had brought scones and jam.

- An insect flew towards them.

- A friend ran away from the food with a scared look on her face. (Neutral)

- It had yellow and brown stripes and flew straight past the group. (No revise)

- It had a bright blue body, lacey wings, and headed to the pond. (Revise)

- Daphne and her friends watched the dragonfly.

Daphne was having a picnic with friends. [Yes]
66. The poverty food/games

- The documentary was about how famine in the 'Third World' was getting worse.

- In southern Africa especially, the incidence of malnutrition has increased hugely over the last few years.

- A young boy almost naked was crying desperate in the middle of nowhere.

- It was a village in the southwest, near Cape Town. (Neutral)

- The poor child did not have many things in his house. (No revise)

- The poor child did not have many things to play with in his house. (Revise)

- The documentary maker told that the boy suffered the shortage of games.

The documentary was showing the situation in southern China. [No]

\section{Mother's knowledge suffering/lying}

- This morning Sarah's son woke up complaining of a bad headache.

- His mother knew what to do.

- She made a phone call and helped her son to get into the car.

- During the journey, Sarah listened to the local news on the radio. (Neutral)

- During the journey, Sarah's son had his hand on his forehead. (No revise)

- During the journey, Sarah's son was pretending to be ill. (Revise)

- After parking the car, Sarah realized that her son was lying.

Sarah did not know what to do with her son's headache. [No]

\section{The story $\mathrm{broom} / \mathrm{cart}$}

- The father was reading a fairy tale to Susie and Charlie.

- On each page, the children looked at the pictures and asked questions about the story.

- The main character was a witch who got to escape through the mountains.

- $\quad$ The witch wore black clothes, in the middle of night, and had an evil laugh. (Neutral) 
- The witch walked away, in her pointed hat, giving a shrill laugh. (No revise)

- The witch walked away guiding a horse that pulled the wooden wheels. (Revise)

- Charlie asked why the witch got away in a cart.

Susie and Charlie were listening their mother reading a fairy tale. [No]

\section{The game chess/poker}

- Today it was being played the most important tournament of the city.

- The last two players were concentrating hard at each end of the table.

- Both of them were looking at the time when they had to make a decision.

- One of the players asked for a glass of water without removing the gaze from the game. (Neutral)

- One of the players was very nervous and carefully observed each move of his opponent. (No revise)

- One of the players wore sunglasses trying to conceal any expression that could indicate his cards. (Revise)

- After an hour and a half they finished the game of poker.

It was the most important tournament of the city. [Yes]

\section{The river frog/turtle}

- In the pond in my village there is a huge variety of plants and animals.

- Sometimes the sound of croaking is really loud.

- Last Tuesday it was very noisy so I went to investigate.

- It was very dark so I could not see very well. (Neutral)

- There was a green animal sitting on a water lily. (No revise)

- There was a small animal with a shell on a water lily. (Revise)

- In the end I realized that it was a turtle.

There was a huge variety of plants and animals in the lake. [No]

\section{The thief $c a s h / p i z z a$}

- Samuel is a petty thief.
- He is currently serving a three month prison sentence.

- A month ago, he was caught robbing a shop.

- The camera footage was the decisive evidence against Samuel. (Neutral)

- A camera recorded how Samuel got in and left the shop with a full bag. (No revise)

- A camera recorded how Samuel got a whole bag filled with Italian food. (Revise)

- The police easily understood how the thief had stolen a lot of pizza.

Samuel was serving a one year prison sentence. [No]

72. The baby milk/water

- The baby used to cry very loudly when he was hungry.

- His father thought how easy it would be if his wife were there to breastfeed the child.

- But the mother was at work and now the father had to feed his little boy.

- He picked up the desperate baby and carried him down to the kitchen. (Neutral)

- He filled the feeding bottle and gave it to his baby to drink. (No revise)

- He filled the feeding bottle with fruit drink and gave it to the baby. (Revise)

- The father was pleased to see the soothed baby drinking the juice.

The mother of the baby had died. [No]

\section{The bride tiara/bonnet}

- At the dentist's surgery, I took one of the cheap magazines from the table.

- One page showed the royal wedding of some remote country.

- Everyone was talking about the expensive outfit worn by the bride.

- The bride stood in front of the palace greeting the people who had come. (Neutral)

- The bride stood out because of the shinning accessory on her head. (No revise)

- The bride stood out because of the sunhat with a brim on her head. (Revise)

- Many women who had attended could not stop looking at her bonnet. 
The magazine was at the dentist's surgery. [Yes]

\section{The swimmer goggles/glasses}

- As she did every afternoon, the swimmer went to the pool.

- In the changing room, she realised that she did not have anything to help her to see in the water.

- She picked up her things and drove home.

- She was expecting the traffic to be light on the route. (Neutral)

- She was expecting to find the blue case by the door. (No revise)

- She was expecting to find her spectacles case in the bedroom. (Revise)

- Driving back to the pool, she was now happy to have her glasses.

The swimmer used to go to the swimming pool in the morning. [No]

\section{The security helmet/harness}

- The builder knew only too well how risky it was to work on the demolition site.

- A few days ago a large stone fell from a wall directly onto his head.

- Fortunately, he was always well protected.

- The builder had some bruises but in the end it was nothing serious. (Neutral)

- The builder's safety was guaranteed by the fastening of the strap. (No revise)

- The fastening of the strap protected the builder's body from legs to shoulders. (Revise)

- It was not the first time that he saved his life with the harness.

The builder was working on the demolition site. [Yes]

\section{The idol trumpet/piano}

- Ethan played an instrument in a Jazz band.

- He really admired Louis Armstrong who was his idol.

- Ethan tried to imitate his characteristic inflated cheeks movement.

- Every day, he dreamt of becoming a professional musician. (Neutral)
- Every day, he stood in front of the mirror playing his instrument. (No revise)

- Every day, he sat close to the instrument playing its keys. (Revise)

- Ethan could pass hours playing his piano.

The idol of Ethan was Ray Charles. [No]

\section{The Greek museum sculpture/picture}

- Kathie was visiting the ancient Greek museum in Athens.

- She had been studying the proportions of the human body for a long time.

- Now she could appreciate these marble works of art.

- In the third corridor, Kathie recognized one of the works. (Neutral)

- In the third corridor, Kathie was very impressed by a figure. (No revise)

- In the third corridor, Kathie was very impressed by a two-dimensional work. (Revise)

- She remembered when she had to study that particular picture.

Kathie was in Athens. [Yes]

78. Global Warming (polar) bear/seal

- Global Warming is bringing about irreparable damage to our ecosystem.

- In the North Pole for example, the reduction of icebergs is resulting in the death of many animals.

- The other day on TV I saw an animal isolated in the melt water.

- $B B C$ documentaries have always managed to film the stark reality. (Neutral)

- The desperation of the big hairy animal made me sad. (No revise)

- The desperation of the gray animal with flippers and whiskers shocked me. (Revise)

- I changed the channel when I started feel very sad for that seal.

The documentary was about Global Warming. [Yes]

\section{Wild West boots/trainers}

- Our office party this year had a Wild West theme. 
- Some of my colleagues were really imaginative and dressed up as a cactus or a horse.

- Robert had the simplest outfit and dressed up as a cowboy.

- He had been working all day and had no time to prepare his costume. (Neutral)

- He was wearing a cowboy hat on his head and a pair of shoes with buckles. (No revise)

- He was wearing a cowboy hat on his head and a pair of sports shoes. (Revise)

- Arriving at the party, Robert felt uncomfortable with his pair of trainers.

Robert's costume was the simplest of the party. [Yes]

\section{The tectonic plates lava/smoke}

- Our teacher explained that the tectonic plates of the Earth are still active.

- specially in volcanic areas, the crash between these plates can cause huge catastrophes.

- e also learnt that damage can be caused by the seepage from the centre of the volcano.

- Many plant species disappear each year for this very reason. (Neutral)

- The volcano's eruptions can cause irreparable disasters in the area. (No revise)

- The gaseous and dark fumes of a volcano's eruptions can cause disasters. (Revise)

- To show it to us, our teacher drew on the board the seepage of smoke.

The tectonic plates can produce the leak of volcanic residues. [Yes]

\section{The Scotsman kilt/coat}

- Most evenings the traditional Scotsman played his bagpipes up on the hill.

- As he did so, he thought of his ancestors and their traditions.

- That night the wind was blowing fiercely and his legs had goose bumps.

- The Scotsman was not cold because he was engrossed with the melody. (Neutral)

- The Scotsman was wearing a traditional garment with nothing underneath. (No revise)
- The Scotsman was wearing an outdoor jacket with little underneath. (Revise)

- That night he had to stop playing because the wind strongly blew about his coat.

The Scotsman had goose bumps. [Yes]

82. The wise books/photos

- Ernest is the oldest librarian in my city.

- Everyone believes that he is the wisest man in the area.

- He used to read all the time, and has an impressive knowledge of the world.

- Ernest has a thousand stories to tell in every situation. (Neutral)

- Ernest has a huge collection from which he learnt. (No revise)

- Ernest has a huge collection of pictures from which he learnt. (Revise)

- Ernest has invited the local schoolchildren to visit his huge collection of photos.

Ernest had an impressive knowledge of the world. [Yes]

\section{The wheel bicycle/scooter}

- The mountain ride was difficult from the beginning.

- The well-known competitor started to sweat profusely.

- He was going at full speed among the sharp rocks.

- $\quad$ The competitor knew that he was about to reach the finish line. (Neutral)

- The competitor was working flat out while he went uphill. (No revise)

- The competitor was working flat out while he accelerated uphill. (Revise)

- With the rain, the stony ground punctured the wheel of his scooter.

There were sharp rocks on the floor. [Yes]

84. The match hoop/goal

- Aggie started to play basketball two weeks ago.

- Now she trains with her team every week.

- During a recent match she caught the ball and quickly positioned herself. 
- Aggie felt the spectators' tension when she threw the ball. (Neutral)

- Aggie carefully directed the ball towards its target. (No revise)

- Aggie carefully kicked the ball towards its target. (Revise)

- The crowd applauded as the ball entered the goal.

Aggie had started to play basketball two months ago. [No]

\section{The food chili/pesto}

- The Mexican Carlos was having lunch.

- He played in a Mariachi band, so he loved to dress in his traditional costume with its big cap.

- Now he was having his typical meal, a tasty burrito.

- The Mexican Carlos tasted the burrito and smiled and licked his lips. (Neutral)

- The Mexican Carlos had put a lot of his favorite sauce on the burrito. (No revise)

- The Mexican Carlos had put a lot of basil sauce on the burrito. (Revise)

- After he had finished eating he could still taste the pesto.

The Mexican liked to wear a big cap. [Yes]

\section{World Heritage Coliseum/Vatican}

- Europe has many important historic buildings recognized as World Heritage.

- My aunt told me that the Roman Empire made a great contribution.

- They built many amphitheatres and circuses in different places.

- She told me about a representative example of World Heritage building. (Neutral)

- In Rome, there is a famous example of incredible dimensions. (No revise)

- In Rome, there is a group of buildings constituting the Holy See. (Revise)

- This World Heritage place is known with the name of Vatican.

The Roman Empire built many World Heritage buildings. [Yes]

\section{The show ballerina/actress}

- There were just a few people in the audience.

- The music was already playing when the dancer turned up.

- Even the barman stopped his work to watch her wonderful movements.

- The woman had an innate ability to make everyone speechless. (Neutral)

- The woman was standing on tiptoe, raising her hands in a circle. (No revise)

- The woman was standing on the stage, playing a femme fatale. (Revise)

- At the end, the public gave a standing ovation to the actress.

The barman did not see the movements of the dancer. [No]

\section{The dinner pasta/couscous}

- The supermarket was packed with people.

- The young Italian had decided to cook a traditional dinner to impress his new flatmates.

- He found the parmesan and now he just needed the big packet.

- The boy asked the staff where he could find the product. (Neutral)

- The boy was planning to cook an Italian dish for his flatmates. (No revise)

- The boy was planning to cook a typical Arabic dish for his flatmates. (Revise)

- After few minutes of searching, the young man found the packet of couscous.

The young boy bought some camembert cheese. [No]

\section{The flowerpot shoots/worms}

- This is my favorite season: spring.

- I love it because everything is in bloom and it is colorful everywhere.

- Today I saw something new in one of my flowerpots.

- I called mum to ask if I should give it any special treatment. (Neutral)

- Small green things could be seen on the surface of the soil. (No revise) 
- Small, smooth pinky-brown creatures were wriggling about in the soil. (Revise)

- My mother came and saw the tiny little worms.

It was colorful everywhere because it was spring. [Yes]

\section{The homework scissors/knives}

- Hard-working Daniel brought his homework back from school.

- He was learning how color and cut out different shapes.

- He colored in the outline of tractor in yellow and carefully cut it out.

- Her mother was next to him watching her son's new ability. (Neutral)

- He picked up the tool to cut out the drawing of the tractor. (No revise)

- He took the blade to cut out the drawing of the tractor. (Revise)

- The child had finally succeeded in learning to use the heavy knives.

Daniel had drawn a brown tractor. [No]

\section{References}

Baker, L. (1985). How do we know when we don't understand? Standards for evaluating text comprehension. In D. L. ForrestPressley, G. E. MacKinnon, \& T. G. Waller (Eds.), Metacognition, cognition, and human performance (Vol. 1, pp. 155-205). New York, NY: Academic Press.

Bohn-Gettler, C. M., Rapp, D. N., Van den Broek, P., Kendeou, P., \& White, M. J. (2011). Adults' and children's monitoring of story events in the service of comprehension. Memory \& Cognition, 39, 992-1011. doi:10.3758/s13421-011-0085-0

Cain, K. (2006). Individual differences in children's memory and reading comprehension: An investigation of semantic and inhibitory deficits. Memory, 14, 553-569. doi:10.1080/09658210600624481

Carretti, B., Cornoldi, C., De Beni, R., \& Palladino, P. (2004). What happens to information to be suppressed in working-memory tasks? Short and long term effects. The Quarterly Journal of Experimental Psychology: Section A, 57, 1059-1084. doi:10.1080/ 02724980343000684

Carretti, B., Belacchi, C., \& Cornoldi, C. (2010). Difficulties in working memory updating in individuals with intellectual disability. Journal of Intellectual Disability Research, 54, 337-345. doi:10.1111/j. 1365-2788.2010.01267.x

Daneman, M., \& Carpenter, P. A. (1980). Individual differences in working memory and reading. Journal of Verbal Learning and Verbal Behavior, 19, 450-466.

Debener, S., Makeig, S., Delorme, A., \& Engel, A. K. (2005). What is novel in the novelty oddball paradigm? Functional significance of the novelty P3 event-related potential as revealed by independent component analysis. Cognitive Brain Research, 22, 309-321. doi: 10.1016/j.cogbrainres.2004.09.006
Dutke, S., \& von Hecker, U. (2011). Comprehending ambiguous texts: A high reading span helps to constrain the situation model. Journal of Cognitive Psychology, 23, 227-242. doi:10.1080/20445911.2011. 485127

Dutke, S., Baadte, C., Hähnel, A., von Hecker, U., \& Rinck, M. (2010). Using diagnostic text information to constrain situation models. Discourse Processes, 47, 510-544. doi:10.1080/ 01638530903416257

Engle, R. W. (2002). Working memory capacity as executive attention. Current Directions in Psychological Science, 11, 19-23. doi:10. 1111/1467-8721.00160

Evans, J. L., Selinger, C., \& Pollak, S. D. (2011). P300 as a measure of processing capacity in auditory and visual domains in specific language impairment. Brain Research, 1389, 93-102. doi:10.1016/j. brainres.2011.02.010

Friedman, D., Cycowicz, Y. M., \& Gaeta, H. (2001). The novelty P3: An event-related brain potential (ERP) sign of the brain's evaluation of novelty. Neuroscience \& Biobehavioral Reviews, 25, 355-373. doi: 10.1016/S0149-7634(01)00019-7

Gernsbacher, M. A. (1990). Language comprehension as structure building. Hillsdale: Erlbaum.

Gernsbacher, M. A. (1997). Attenuating interference during comprehension: The role of suppression. Psychology of Learning and Motivation, 37, 85-104. San Diego, CA: Academic Press.

Gernsbacher, M. A., \& Faust, M. E. (1991). The mechanism of suppression: A component of general comprehension skill. Journal of Experimental Psychology: Learning, Memory, and Cognition, 17, 245-262. doi:10.1037/0278-7393.17.2.245

Gernsbacher, M. A., Varner, K. R., \& Faust, M. E. (1990). Investigating differences in general comprehension skill. Journal of Experimental Psychology: Learning, Memory, and Cognition, 16, 430-445. doi: 10.1037/0278-7393.16.3.430

Getzmann, S., \& Falkenstein, M. (2011). Understanding of spoken language under challenging listening conditions in younger and older listeners: A combined behavioral and electrophysiological study. Brain Research, 1415, 8-22. doi:10.1016/j.brainres.2011.08.001

Guéraud, S., Harmon, M. E., \& Peracchi, K. A. (2005). Updating situation models: The memory-based contribution. Discourse Processes, 39, 243-263. doi:10.1207/s15326950dp3902\&3 8

Hacker, D. J. (1998). Self-regulated comprehension during normal reading. Metacognition in Educational Theory and Practice (pp. 165191). Mahwah: Erlbaum.

Hartikainen, K. M., \& Knight, R. T. (2003). Lateral and orbital prefrontal cortex contributions to attention. Detection of Change (pp. 99-116). Dordrecht: Kluwer Academic.

Kendeou, P. (2014). Validation and comprehension: An integrated overview. Discourse Processes, 51, 189-200. doi:10.1080/0163853X. 2013.855874

Kendeou, P., \& O'Brien, E. J. (2014). The Knowledge Revision Components $(\mathrm{KReC})$ framework: Processes and mechanisms. In D. N. Rapp \& J. Braasch (Eds.), Processing inaccurate information: Theoretical and applied perspectives from cognitive science and the educational sciences (pp. 353-378). Cambridge: MIT Press.

Kendeou, P., Smith, E. R., \& O'Brien, E. J. (2013). Updating during reading comprehension: Why causality matters. Journal of Experimental Psychology: Learning, Memory, and Cognition, 39, 854-865. doi:10.1037/a0029468

Kintsch, W. (1998). Comprehension: A paradigm for cognition. New York: Cambridge University Press.

Kintsch, W., \& van Dijk, T. A. (1978). Toward a model of comprehension and production. Psychological Review, 85, 363-394. doi:10.1037/ 0033-295X.85.5.363

Kok, A. (2001). On the utility of P3 amplitude as a measure of processing capacity. Psychophysiology, 31, 557-577. doi:10.1017/ S0048577201990559 
Kuperberg, G. R., Paczynski, M., \& Ditman, T. (2011). Establishing causal coherence across sentences: An ERP study. Journal of Cognitive Neuroscience, 23, 1230-1246. doi:10.1162/jocn.2010. 21452

Kutas, M., \& Federmeier, K. D. (2009). N400. Scholarpedia, 4, 7790.

Kutas, M., \& Federmeier, K. D. (2011). Thirty years and counting: Finding meaning in the N400 component of the event-related brain potential (ERP). Annual Review of Psychology, 62, 621-647. doi:10. 1146/annurev.psych.093008.131123

Kuznetsova, A., Christensen, R. H. B., \& Brockhoff, P. B. (2012). lmerTest: Tests for random and fixed effects for linear mixed effect models (lmer objects of lme4 package). $R$ Package Version, 1-0.

Lorsbach, T. C., Katz, G. A., \& Cupak, A. J. (1998). Developmental differences in the ability to inhibit the initial misinterpretation of garden path passages. Journal of Experimental Child Psychology, 71, 275-296. doi:10.1006/jecp.1998.2462

McKoon, G., \& Ratcliff, R. (1980). The comprehension processes and memory structures involved in anaphoric reference. Journal of Verbal Learning and Verbal Behavior, 19, 668-682.

McKoon, G., \& Ratcliff, R. (1992). Inference during reading. Psychological Review, 99, 440-466. doi:10.1037/0033-295X.99.3. 440

McNamara, D. S., \& Magliano, J. (2009). Toward a comprehensive model of comprehension. Psychology of Learning and Motivation, 51, 297-384.

O’Brien, E. J., Rizzella, M. L., Albrecht, J. E., \& Halleran, J. G. (1998). Updating a situation model: A memory-based text processing view. Journal of Experimental Psychology: Learning, Memory, and Cognition, 24, 1200-1210. doi:10.1037/0278-7393.24.5.1200

O'Brien, E. J., Cook, A. E., \& Guéraud, S. (2010). Accessibility of outdated information. Journal of Experimental Psychology: Learning, Memory, and Cognition, 36, 979. doi:10.1037/a0019763

Perfetti, C. A., Stafura, J. Z., \& Adlof, S. M. (2013). Reading comprehension and reading comprehension problems: A word-to-text integration perspective. In B. Miller, L. E. Cutting, \& P. McCardle (Eds.), Unravelling reading comprehension: Behavioral, neurobiological, and genetic components (pp. 22-32). Baltimore, MD: Brookes.

Pimperton, H., \& Nation, K. (2010). Suppressing irrelevant information from working memory: Evidence for domain-specific deficits in poor comprehenders. Journal of Memory and Language, 62, 380 391. doi:10.1016/j.jml.2010.02.005

Polich, J. (2003). Theoretical overview of P3a and P3b. Detection of Change, 83-98. Dordrecht: Kluwer Academic.
Polich, J. (2007). Updating P300: An integrative theory of P3a and P3b. Clinical Neurophysiology, 118, 2128-2148. doi:10.1016/j.clinph. 2007.04.019

Poynor, D. V., \& Morris, R. K. (2003). Inferred goals in narratives: Evidence from self-paced reading, recall, and eye movements. Journal of Experimental Psychology: Learning, Memory, and Cognition, 29, 3-9. doi:10.1037/0278-7393.29.1.3

Radvansky, G. A., \& Copeland, D. E. (2004). Working memory span and situation model processing. The American Journal of Psychology, 117, 191-213. doi:10.2307/4149022

Rapp, D. N., \& Kendeou, P. (2007). Revising what readers know: Updating text representations during narrative comprehension. Memory \& Cognition, 35, 2019-2032. doi:10.3758/BF03192934

Rapp, D. N., \& Kendeou, P. (2009). Noticing and revising discrepancies as texts unfold. Discourse Processes, 46, 1-24. doi:10.1080/ 01638530802629141

Rapp, D. N., \& Taylor, H. A. (2004). Interactive dimensions in the construction of mental representations for text. Journal of Experimental Psychology: Learning, Memory, and Cognition, 30, 988-1001. doi: 10.1037/0278-7393.30.5.988

Rapp, D. N., \& van den Broek, P. (2005). Dynamic text comprehension an integrative view of reading. Current Directions in Psychological Science, 14, 276-279. doi:10.1111/j.0963-7214.2005.00380.x

Schneider, W., Eschman, A., \& Zuccolotto, A. (2002). E-Prime user's guide. Pittsburgh: Psychology Software Tools.

Singer, M. (2013). Validation in reading comprehension. Current Directions in Psychological Science, 22, 361-366.

St. George, M., Mannes, S., \& Hoffman, J. E. (1997). Individual differences in inference generation: An ERP analysis. Journal of Cognitive Neuroscience, 9, 776-787.

Szmalec, A., Verbruggen, F., Vandierendonck, A., \& Kemps, E. (2011). Control of interference during working memory updating. Journal of Experimental Psychology: Human Perception and Performance, 37, 137. doi:10.1037/a0020365

Vauras, M., Kinnunen, R., Salonen, P., \& Lehtinen, E. (2008). Emotions in comprehension monitoring and regulation. International Journal of Psychology, 43, 17.

Virtue, S., Haberman, J., Clancy, Z., Parrish, T., \& Jung Beeman, M. (2006). Neural activity of inferences during story comprehension. Brain Research, 1084, 104-114. doi:10.1016/j.brainres.2006.02.053

Wagoner, S. A. (1983). Comprehension monitoring: What it is and what we know about it. Reading Research Quarterly, 18, 328-346.

Zeno, S. M., Ivens, S. H., Millard, R. T., \& Duvvuri, R. (1995). The educator's word frequency guide. Brewster: Touchstone Applied Science Associates. 